\title{
Rate Dependent Behaviour and Dynamic Strain Localisation of Three Novel Impact Resilient Titanium Alloys: Experiments and Modelling
}

\author{
Longhui Zhang ${ }^{\mathrm{a}}$, Govind Gour ${ }^{\mathrm{a}}$, Nik Petrinic ${ }^{\mathrm{a}}$, Antonio Pellegrino ${ }^{\mathrm{a}} *$ \\ a'Department of Engineering Science, University of Oxford, Oxford OX1 3PJ, United \\ Kingdom \\ *antonio.pellegrino@eng.ox.ac.uk
}

\begin{abstract}
:
The tensile behaviour of three ductile titanium alloys, Ti0.7Al4V, Ti1Al4V and Ti3Al2.5V, conceived for impact containment applications, is characterized at quasi-static, intermediate and high strain rates. Tests have been performed using a screw driven mechanical system and a bespoke in-house developed split Hopkinson tension bar equipped with ultra-high speed photographic equipment ${ }^{1}$. The three alloys present noticeable strain rate sensitivity. Ti1Al4V is characterised by the lowest flow stress and highest ductility of the three alloys. Ti3A12.5V higher flow stress but lowest strain to failure while Ti0.7Al4V has similar flow stress but larger engineering failure strain compared to Ti3 $\mathrm{Al} 2.5 \mathrm{~V}$. The dynamic true strain rate, determined by measuring the time history of the minimum cross-section diameter during necking, reaches values up to one order of magnitude higher than the nominal strain rate. This phenomenon, occurring during dynamic strain localisation, is of fundamental importance for understanding and modelling the dynamic behaviour of ductile alloys designed to withstand impact loading. The experimental results are used to determine the material parameters of the Johnson-Cook (JC) and Khan-Huang-Liang (KHL) models, which are incorporated in the ABAQUS/explicit code for finite element simulations of the dynamic tensile tests. It is found that the KHL model predicts the experimentally measured strain field, deformed geometry, effective strain rate and macroscopic force-displacement response during the high strain rate experiments with significantly better agreement than the JC model.
\end{abstract}

\footnotetext{
${ }^{1}$ Specialised Imaging SIMX 16 High speed camera
} 
Keywords: Titanium Alloys; High Strain Rate; Hopkinson Bar; Effective Strain Rate; Constitutive Modeling; Finite Element Simulation

\section{Introduction}

Titanium (Ti) alloys are extensively utilized due to their combination of high specific strength and outstanding resistance to corrosion, fatigue and environmental effects. They feature good weldability, and a good balance between strength and ductility. The use of titanium alloys in situations where they are subjected to high-speed deformation necessitates the understanding of their dynamic behaviour, which is considerably different from the quasi-static, due to their rate dependent mechanical response.

Much attention has been devoted to the mechanical behaviours of titanium alloys for strain rates of several $1000 \mathrm{~s}^{-1}$ by using the Kolsky bar technique[1, 2]. Meyers et al.[3] studied the dynamic compressive and shear behaviour of commercially pure (CP) titanium by using hatshaped specimens. Chichili et al.[4] performed dynamic compression tests on CP titanium at strain rates up to $6000 \mathrm{~s}^{-1}$, and found that $\mathrm{CP}$ titanium displays substantial rate sensitivity of the flow stress and pronounced strain hardening, the latter increasing significantly with both strain and strain rate. Nemat-Nasser et al.[5] studied the quasi-static and dynamic compression behaviour of $\mathrm{CP}$ titanium at different temperatures. The flow stress displayed complex variations with strain, strain rate, and temperature. Macdougall and Harding [6] used a radiometric technique and high-speed photography to record the real time specimen surface temperature and geometry change of Ti6Al4V alloy specimens during dynamic tension and high rate torsion tests. The data obtained was used to calibrate material constants for a ZerilliArmstrong type constitutive relation. Longère and Dragon[7] compared the dynamic and quasistatic shear failure of Ti6Al4V under negative stress triaxiality loading, and found that the material failure is the consequence of a void growth induced process. Rittel and Wang[8] reported direct monitoring of the stress-strain-temperature evolution during dynamic testing leading to adiabatic shear failure of Ti6Al4V, and Zhang et al.[9] measured the real time temperature of aerospace structural titanium alloys Ti3Al2.5V and Ti-55511 subjected to dynamic shear loading. Recently, Rittel et al.[10] compared the real time stress-straintemperature evolution of different titanium alloys under dynamic tension loading by using a non-contact infrared thermometry technique. It is evident that most of the previous research work has been dedicated to Ti6A14V and commercially pure titanium, with a few studies on 
Ti3Al2.5V[9] and a scarcity of literature on the dynamic response of titanium Ti0.7Al4Vand Ti1Al4V alloys.

High strain rate tensile deformation on ductile metal alloys is associated with strain localization and necking. Noble et al. [11] monitored the dynamic nature of tensile deformation by using high-speed photography and compared the numerically and experimentally observed specimen geometries during deformation. Recently, G.Mirone [12] analysed the effects of necking on the strain rate and on the related material response during Hopkinson bar tensile tests, and investigated in detail the stress and strain distributions within the specimens cross section by using validated finite element simulation results. Digital Image correlation (DIC) is a popular full-field measurement technique due to its non-contact features. A number of researchers have used this method to investigate the dynamic tensile behaviour and the necking phenomenon for mild steel [13], dual-phase high-strength steels [14, 15], and ductile polymers [16].

The previous studies on dynamic response of Titanium alloys focused on strain rates lower than $100 \mathrm{~s}^{-1}$ or higher than $1000 \mathrm{~s}^{-1}$. However, literature is still limited at intermediate strain rates between $100 \mathrm{~s}^{-1}$ and $1000 \mathrm{~s}^{-1}$, particularly in tension loading mode, due to limitations of the standard experimental apparatuses. Shim et al.[17] reported the mechanical behaviour of pure titanium at strain rates from $100-1000 \mathrm{~s}^{-1}$ by using a modified split Hopkinson tension bar and calibrated the material constants for constitutive modelling. Recently, Gerlach et al. [18] designed a new split Hopkinson tensile bar (SHTB) capable of generating stress pulses of duration approximately equal to $1.1 \mathrm{~ms}$ to allow for the characterization of material response at strain rates that are difficult, for both hydraulic testing machines and classical Hopkinson tension bar apparatuses, to achieve. Later this novel Hopkinson tension bar was employed by Pellegrino et al.[19] to successfully study the intermediate and high strain rate responses of a polyurethane foam. The determination of the dynamic response of novel titanium alloys at medium and high strain rates provides useful data for the effective design and accurate modelling of structural components for aerospace and automotive applications. The present work has the following two goals:

- The study and comparison of the strain rate dependent mechanical response of three novel titanium alloys for containment applications;

- The derivation and appraisal of the viscoplastic constitutive equations for the rate dependent tensile behaviour of the three titanium alloys under investigation. 
The paper is therefore structured as follows: the materials, specimen geometries and experimental equipment are described in Section 2. The next section presents the experimental results at three distinct strain rates. The constitutive models incorporated in the ABAQUS/explicit FE code for the numerical simulations of the dynamic tensile tests are introduced in Section 4. Section 5 discusses the main outcome of the experimental and numerical work, following by conclusion remarks.

\section{Experimental Protocol}

2.1 Materials and specimens

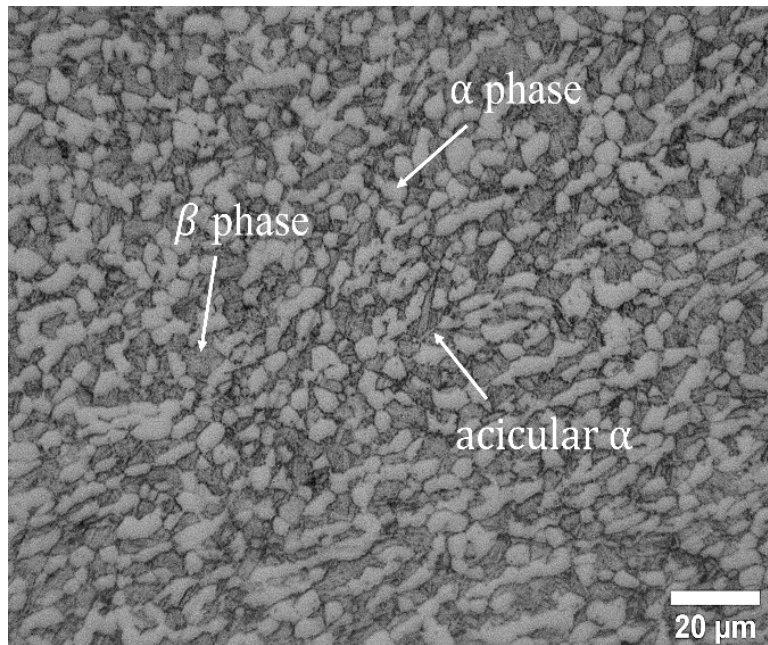

(a)-1 Ti0.7Al4V

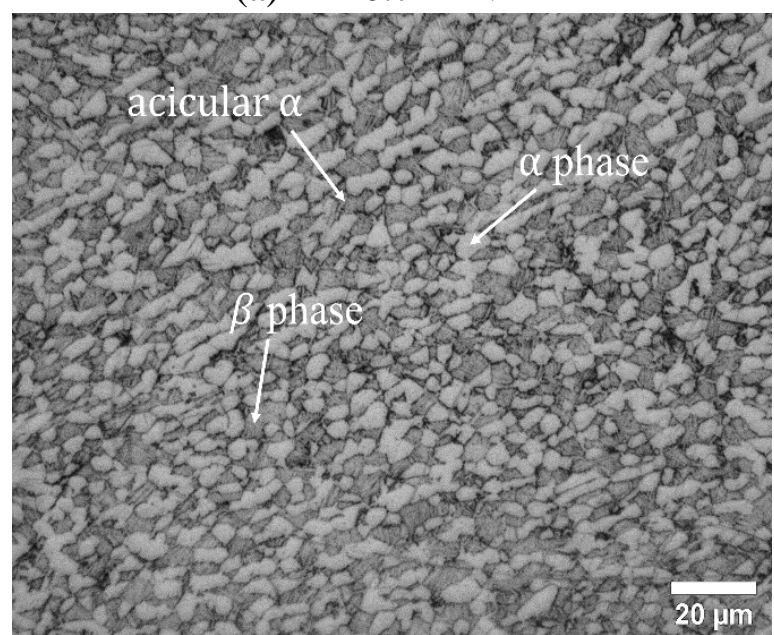

(b)-1 Ti1Al4V

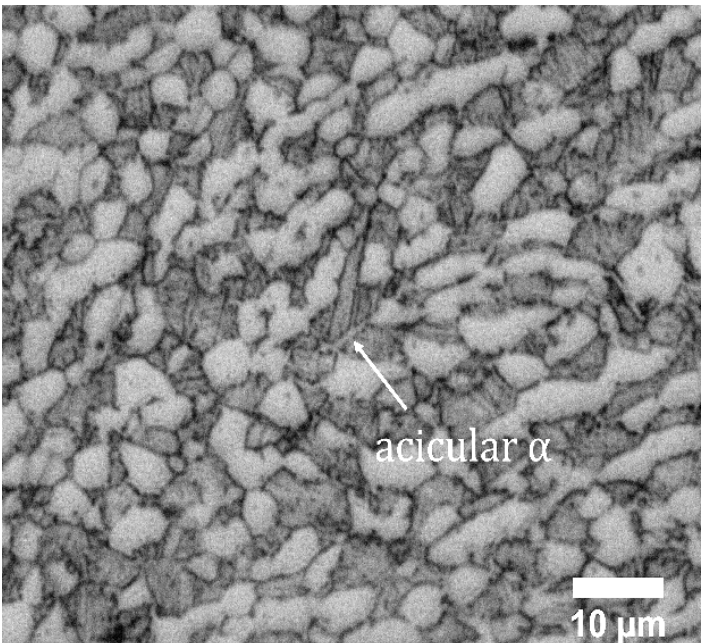

(a)-2 Higher magnification of acicular $\alpha$

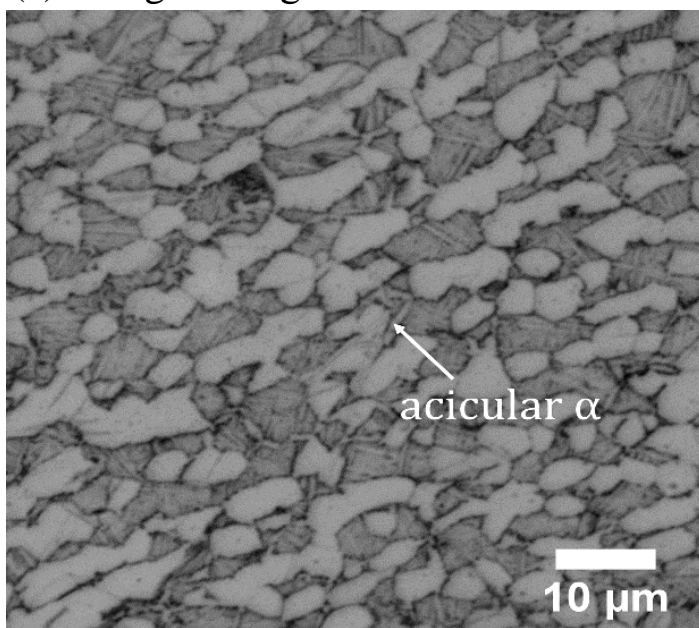

(b)-2 Higher magnification of acicular $\alpha$ 


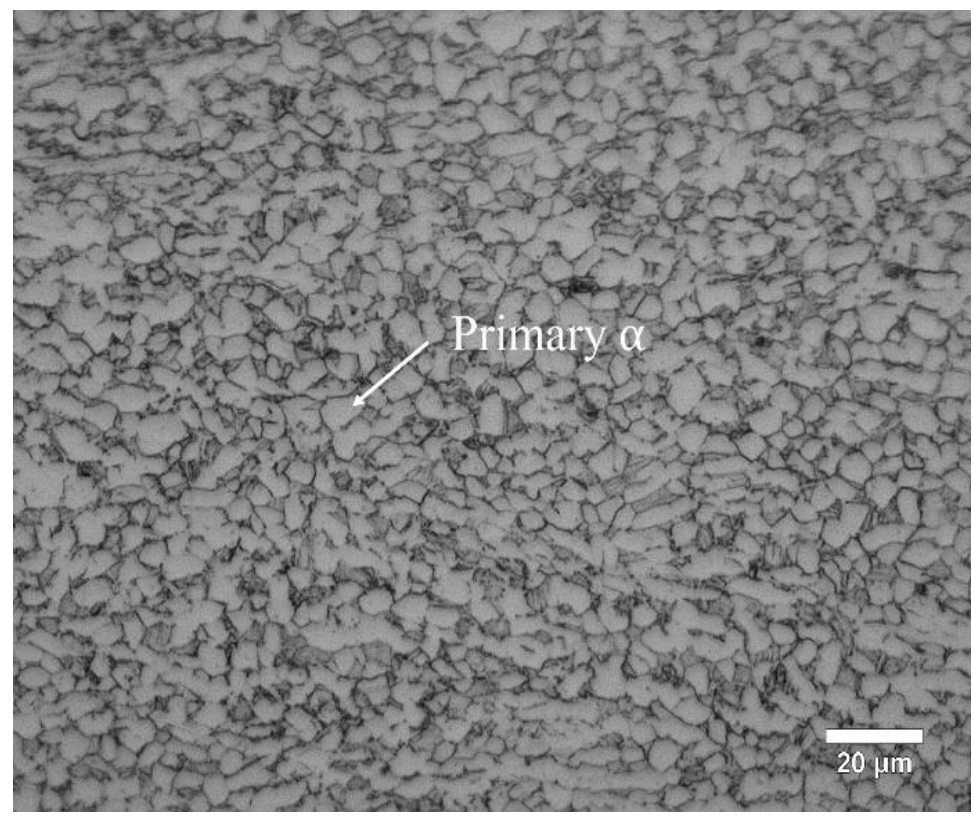

(c) $\mathrm{Ti} 3 \mathrm{Al} 2.5 \mathrm{~V}$

Fig.1 Initial microstructures of the three titanium alloys investigated.

The three $\alpha+\beta$ titanium alloys under investigation are characterised by the initial microstructures shown in Fig.1. Specifically, the microstructures of Ti0.7Al4V [20] and Ti1Al4V are characterised by equiaxed $\alpha$ phase distributed within the $\beta$ phase matrix containing acicular $\alpha$, as shown in Fig. 1(a,b). Ti3A12.5V alloy consists of primary $\alpha$ grains and small amount of dispersed $\beta$ phase [9], as shown in Fig. 1(c).

The chemical compositions of the three titanium alloys [20,21] are given in Table 1 . The tensile specimens employed were machined according to the standard geometries and dimensions shown in Fig.2.

Table1. Composition of the titanium alloys used in this study (wt \%)

\begin{tabular}{ccccccccc}
\hline Material & $\mathrm{Ti}$ & $\mathrm{Al}$ & $\mathrm{V}$ & $\mathrm{O}$ & $\mathrm{Fe}$ & $\mathrm{Si}$ & $\mathrm{C}$ & $\mathrm{Cr}$ \\
Ti1Al4V & Balanced & 1 & 4 & 0.075 & 0.05 & 0.25 & 0.001 & 0 \\
Ti0.7Al4V & Balanced & 0.7 & 4 & 0.12 & 0.08 & 0.25 & 0.03 & 0 \\
Ti3Al2.5V & Balanced & 3 & 2.5 & 0.12 & 0.08 & 0 & 0.03 & 0 \\
\hline
\end{tabular}




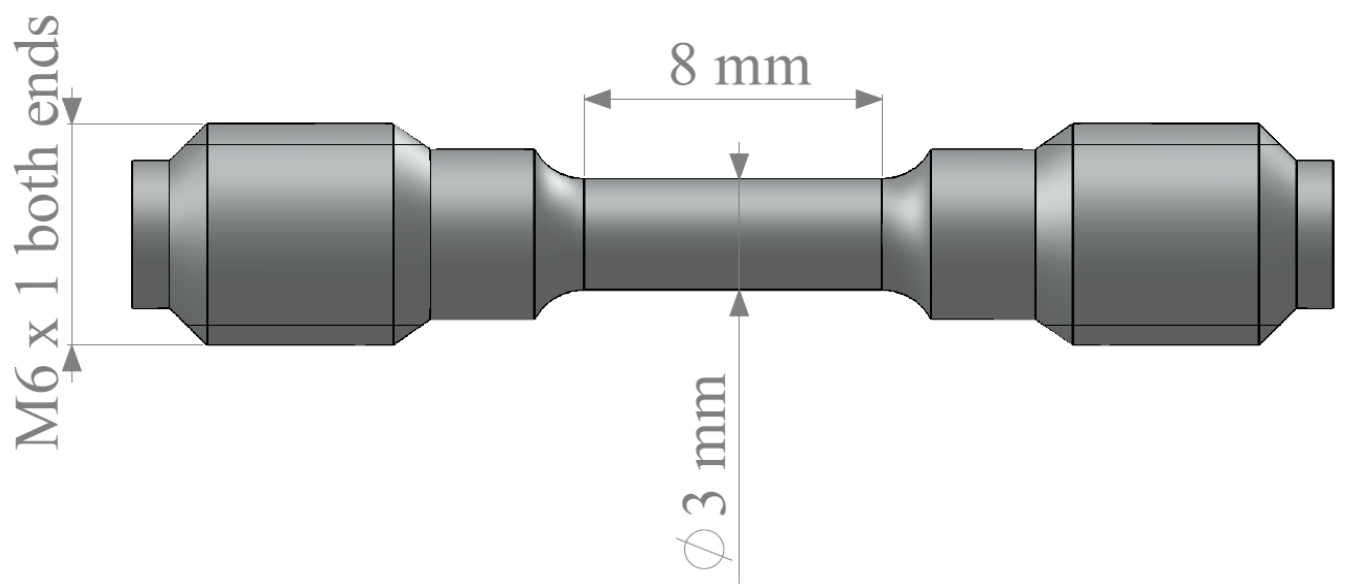

Fig. 2. Geometry of the tensile specimen (all dimensions in $\mathrm{mm}$ ).

\subsection{Experimental setup}

Quasi-static tensile tests were conducted using a screw-driven Zwick mechanical test machine, equipped with a $20 \mathrm{kN}$ load cell and high definition cameras with telecentric lenses for the acquisition of high resolution undistorted images. The strains in the gauge section of the tensile specimen were measured via analysis of the above images using the commercial software GOM Aramis. $^{2}$

Intermediate and high rate tensile experiments were carried out using a bespoke developed split Hopkinson tension bar (Fig.3) designed by Gerlach et al. [18]. The input and output bars are made from titanium, with a solid circular cross-section of diameter $10 \mathrm{~mm}$ and length equal to $2.7 \mathrm{~m}$; All experiments were recorded with ultra-high speed photographic equipment ${ }^{3}$. Different strain rates were obtained by different projectile lengths and velocities: intermediate strain rates were obtained using a $2.5 \mathrm{~m}$ long projectile and lower striker velocities while high strain rates were obtained using a $0.5 \mathrm{~m}$ projectile and higher striker velocities.

\footnotetext{
${ }^{2}$ GOM UK Ltd., 14 The Cobalt Centre, Siskin Parkway East, Coventry, CV3 4 PE, UK.

${ }^{3}$ Specialised Imaging SIMX 16 High speed camera
} 


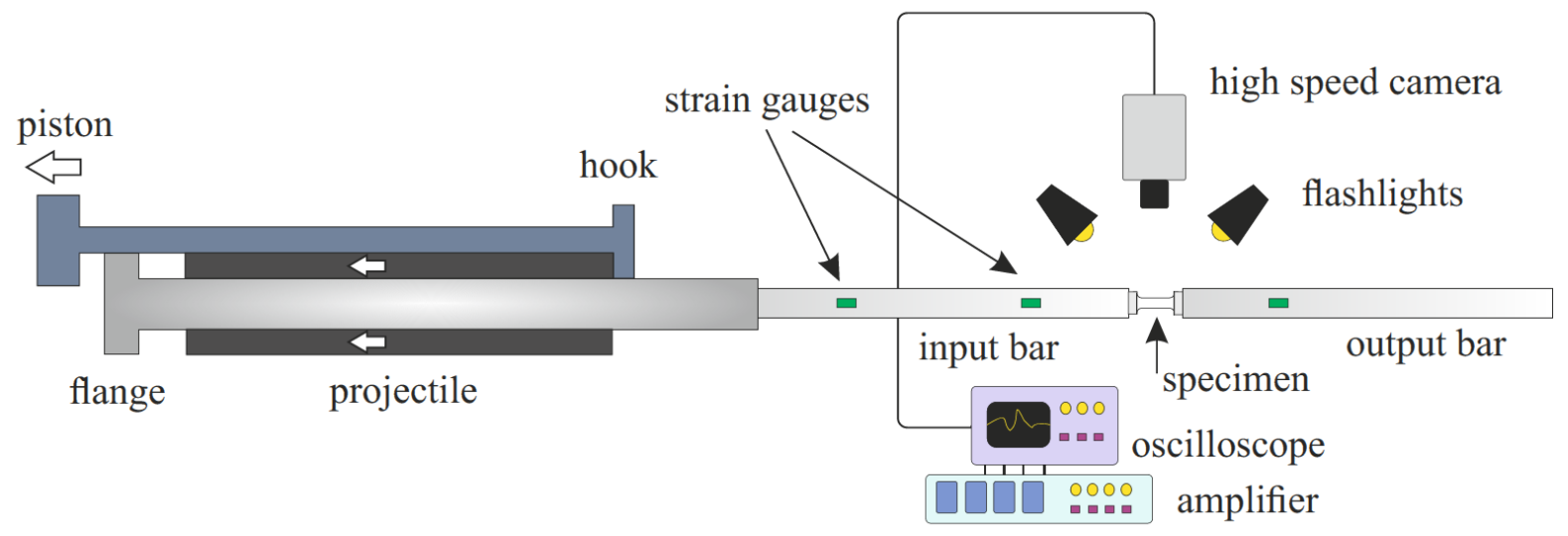

Fig.3. Schematic representation of the Split Hopkinson Tension Bar setup used.

The incident and reflected stress waves do not superimpose during tests conducted using the short projectile. Strain and stress histories can be obtained via the classical spilt hopkinson bar analysis[22]. When the long striker is used, the incident and reflected waves superimpose. Therefore, it is not possible to ditinguish the incident and the reflected waves from the strain measurements on the input bar (Fig.4). A data analysis procedure, based on the method of characteristics and on D'Alambert's solution of wave equations is employed to determine the magnitude of forward and backward travelling waves at the interfaces between bars and specimen as functions of time. Detail on the procedure can be found in [23].

A summary of the experiments conducted in this study and the corresponding nominal strain rates is given in Table 2 .

Table 2. Summary of the experiments conducted in this study

\begin{tabular}{ccc}
\hline Material & Strain rate $\left(\mathrm{s}^{-1}\right)$ & Repetitions \\
& 0.00085 & 3 \\
Ti0.7Al4V & $200-500$ & 3 \\
& 800 & 2 \\
& $1600-2400$ & 5 \\
\hline Ti1A14V & 0.00085 & 3 \\
& 250 & 2 \\
& 850 & 3 \\
Ti3Al2.5V & 2500 & 1 \\
\hline & 0.00085 & 3 \\
& 250 & 2 \\
\hline
\end{tabular}




\begin{tabular}{ll}
\hline $1500-1800$ & 4 \\
\hline
\end{tabular}

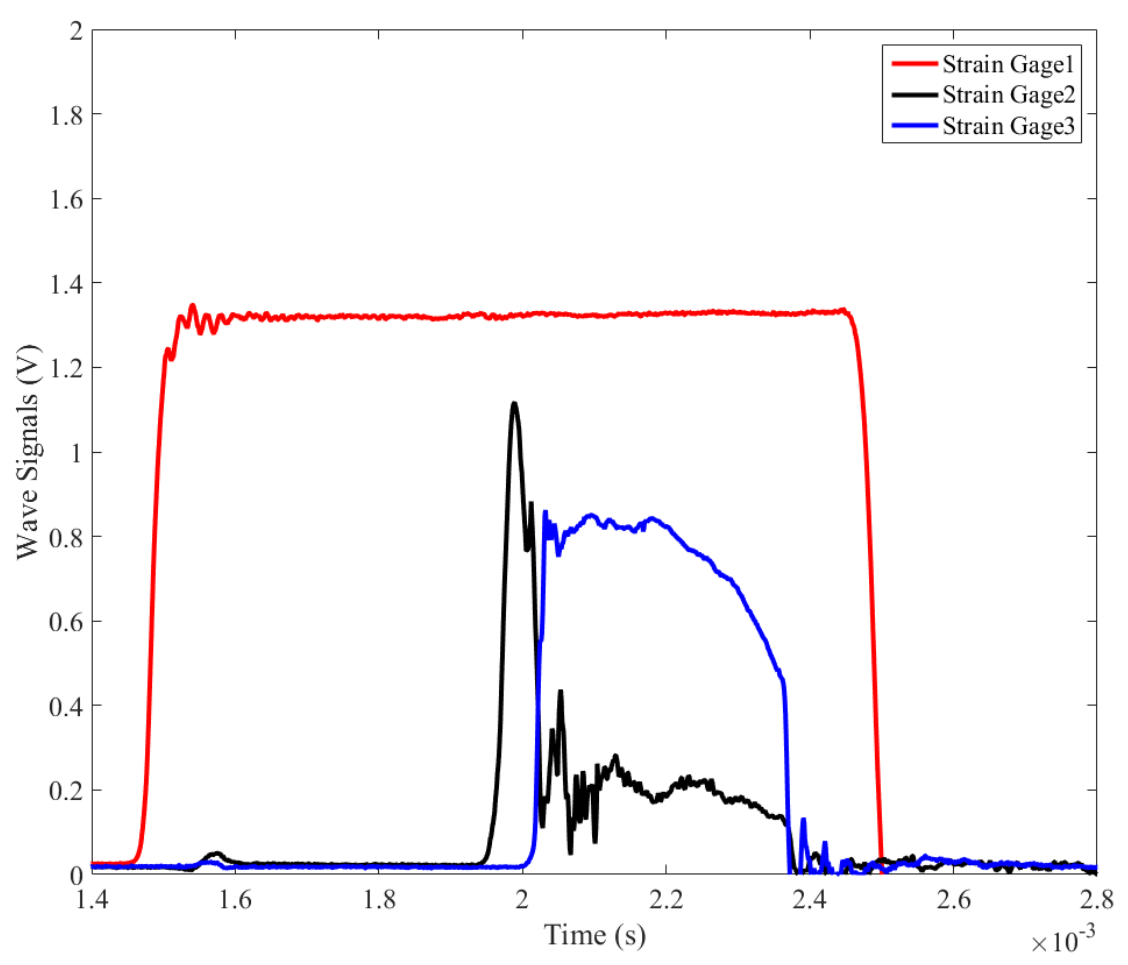

Fig.4 Raw signals recorded during a dynamic tensile experiment on Ti1Al4V conducted at a strain rate of $\sim 850 \mathrm{~s}^{-1}$.

\subsection{Quasi-static Experimental Results}

\section{Experimental Results}

Fig. 5(a) presents a comparison of the engineering stress-strain curves obtained on Ti1 Al4V, Ti0.7Al4V and Ti3A12.5V specimens. The true stress-strain curves for the three titanium alloys are displayed in Fig.5 (b). True stress and true strain data were calculated as follows:

$$
\begin{aligned}
\varepsilon_{\text {true }} & =2 \cdot \ln \left(\frac{r_{o}}{r}\right) \\
\sigma_{\text {true }} & =\frac{F}{\pi \cdot r^{2}}
\end{aligned}
$$

where $r$ and $r_{0}$ are the current and the initial radius of the minimum cross section of the specimen, respectively. $\mathrm{F}$ is the instantaneous force acting on the specimen.

The experimental results obtained at quasi-static strain rates are summarized in Table 3 . The true stress-true strain response is determined via image analysis. Ti3 A12.5V alloy exhibits the highest ultimate engineering stress and flow stress of the three alloys but lower engineering strain to failure, with values in the region of $25 \%$. It shows an average true strain to failure 
equal to $52.5 \%$ and an average maximum true stress of $1000 \mathrm{MPa}$.

Ti1Al4V is the most ductile among the three alloys and presents the lowest yield and ultimate stresses. The material undergoes significant plastic deformation and necking before the specimens fail at engineering strains of approximately $31 \%$. It is characterized by an average true strain to failure equal to $95.7 \%$ and an average maximum true stress of $1151 \mathrm{MPa}$. Ti0.7Al4V exhibits an intermediate behavior between the above two titanium alloys. It presents an average true strain to failure equal to $84 \%$ and an average maximum true stress of 1169 MPa.

Fig. 6 shows the tensile failure mode for the three titanium alloys. Necking and failure are located in proximity of the centre of the specimens.

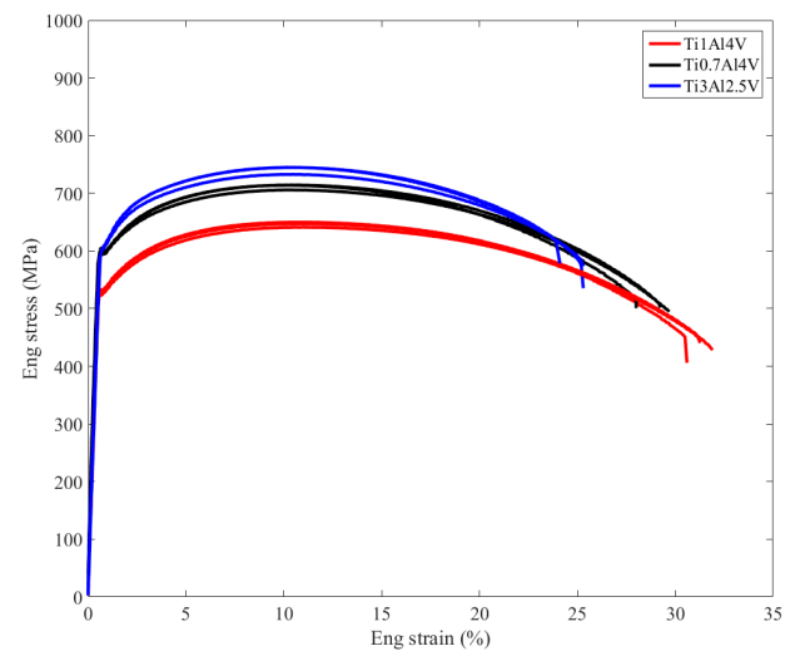

(a) Engineering stress-strain

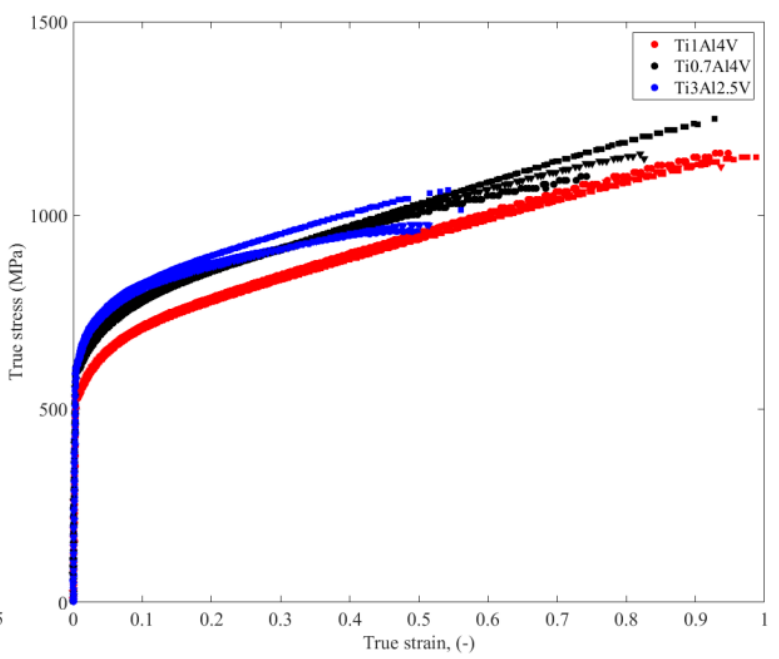

(b) True stress-strain

Fig.5 Comparisons of the quasi-static tensile stress-strain curves of Ti1Al4V, Ti0.7Al4V and Ti3A12.5V titanium alloys.

Table 3. Summary of average quasi-static stress-strain data.

\begin{tabular}{cccccc}
\hline Material & $\begin{array}{c}\text { Yield Stress } \\
(\mathrm{MPa})\end{array}$ & $\begin{array}{c}\text { Engineering } \\
\text { Ultimate Stress } \\
(\mathrm{MPa})\end{array}$ & $\begin{array}{c}\text { True } \\
\text { Ultimate } \\
\text { Stress (MPa) }\end{array}$ & $\begin{array}{c}\text { Engineering } \\
\text { Failure Strain }\end{array}$ & $\begin{array}{c}\text { True Failure } \\
\text { Strain }\end{array}$ \\
Ti0.7Al4V & 584 & 709 & 1169 & $29 \%$ & $84 \%$ \\
Ti1A14V & 522 & 646 & 1151 & $31 \%$ & $95.7 \%$ \\
Ti3Al2.5V & 587 & 741 & 1000 & $25 \%$ & $52.5 \%$ \\
\hline
\end{tabular}

\subsection{Dynamic Experimental Results}

The tensile dynamic behavior of the three alloys under investigation is compared in Fig. 6. 
Fig. 6 (a) shows a comparison of engineering stress-strain curves obtained at strain rates included between $500 \mathrm{~s}^{-1}$ and $850 \mathrm{~s}^{-1}$. Fig.6 (b) presents the corresponding true stress-true strain curves calculated taking into account the reduction in cross-sectional area during necking. The latter was determined by means of image analysis of high speed footage.

The alloy Ti1 Al4V is the most ductile amongst the three alloys. It is characterized by the lowest flow stress but exhibits the largest strain to failure, with average engineering and true failure strains equal to $29 \%$ and $97 \%$ respectively.

Ti3A12.5V and Ti0.7Al4V alloys present similar flow stresses before strain localization. Beyond necking Ti3A12.5V exhibits slightly higher flow stress but lower ductility, as it is apparent in Fig.6 (b) with lower true failure strain. The experimental results obtained on the three alloys at strain rates $\sim 500-850 \mathrm{~s}^{-1}$ are summarized in Table 4.

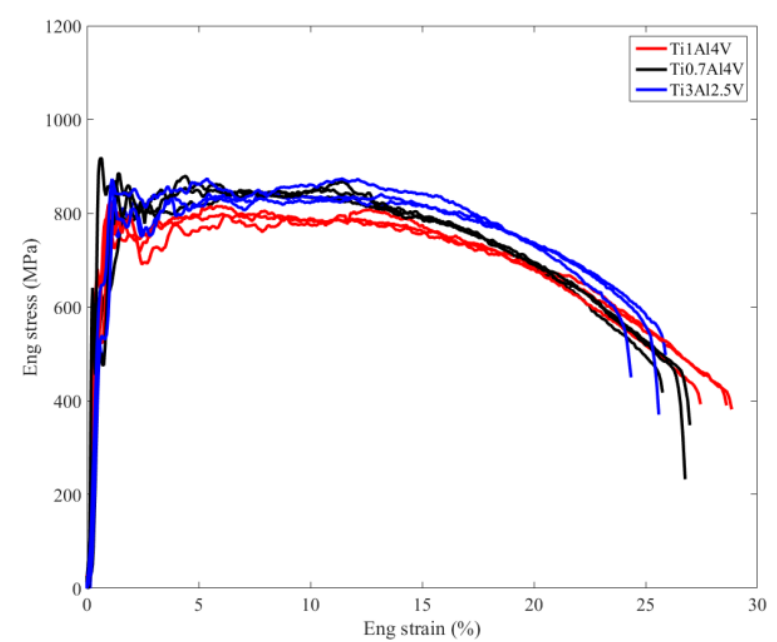

(a) Engineering stress-strain

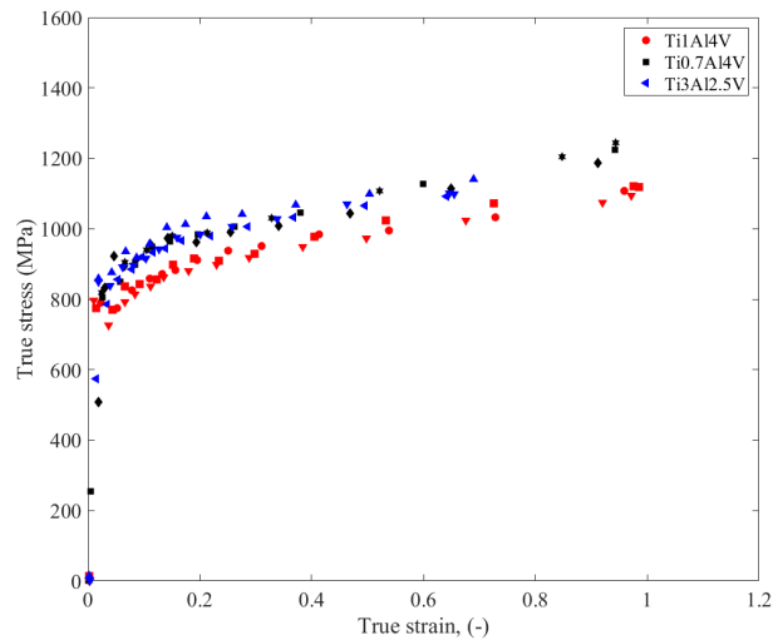

(b) True stress-strain

Fig. 6 Comparisons of the dynamic tensile stress-strain curves of Ti1Al4V, Ti0.7Al4V and Ti3A12.5V titanium alloys at nominal strain rate $\sim 500-850 \mathrm{~s}^{-1}$.

Table 4. Summary of average dynamic stress-strain data obtained at nominal strain rate $\sim 500$ $850 \mathrm{~s}^{-1}$.

\begin{tabular}{cccccc}
\hline Material & $\begin{array}{c}\text { Yield Stress } \\
(\mathrm{MPa})\end{array}$ & $\begin{array}{c}\text { Engineering } \\
\text { Ultimate Stress } \\
(\mathrm{MPa})\end{array}$ & $\begin{array}{c}\text { True } \\
\text { Ultimate } \\
\text { Stress (MPa) }\end{array}$ & $\begin{array}{c}\text { Engineering } \\
\text { Failure Strain }\end{array}$ & $\begin{array}{c}\text { True Failure } \\
\text { Strain }\end{array}$ \\
Ti0.7Al4V & 820 & 840 & 1218 & $27 \%$ & $93 \%$ \\
Ti1A14V & 720 & 760 & 1107 & $29 \%$ & $97 \%$ \\
Ti3A12.5V & 800 & 840 & 1111 & $25 \%$ & $67 \%$ \\
\hline
\end{tabular}




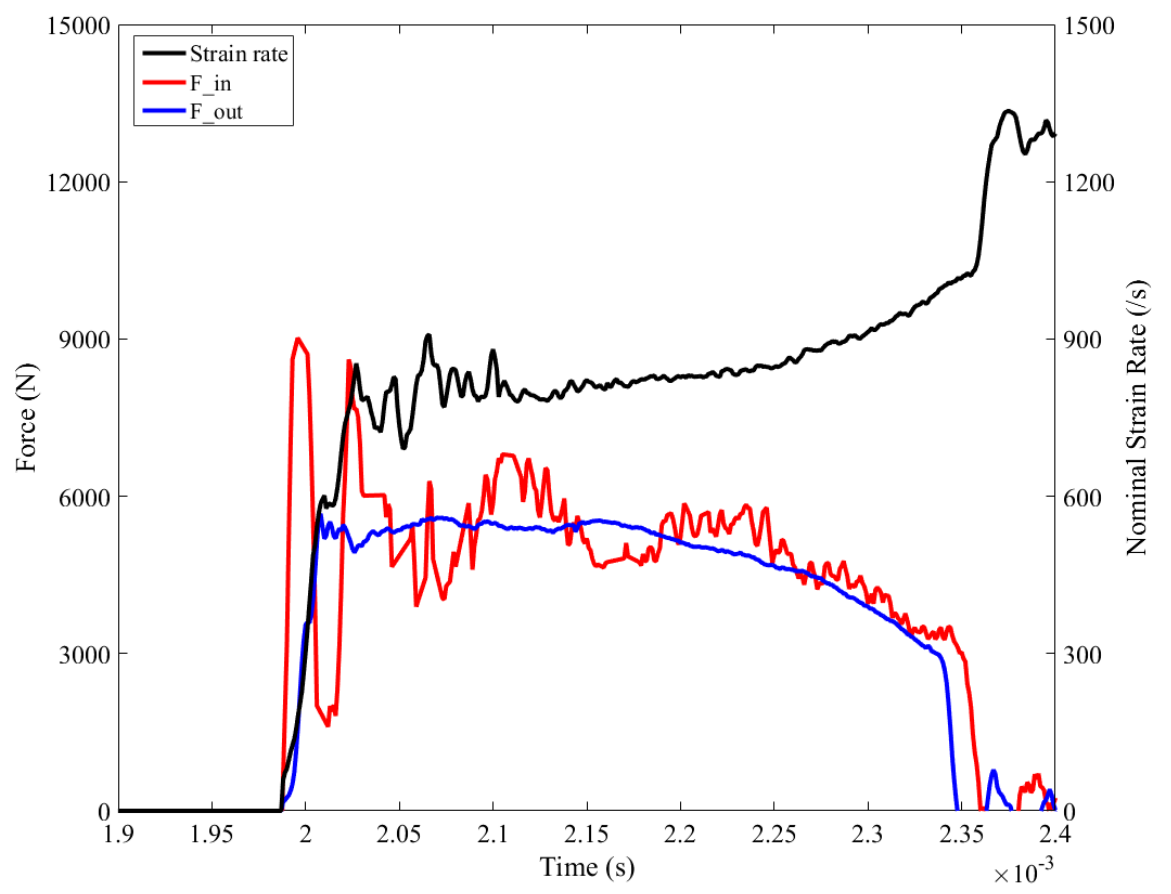

Fig.7 representative dynamic equilibrium conditions during split Hopkinson tension bar experiments (Ti1Al4V).

Conditions of force equilibrium were verified for all presented split Hopkinson tension bar experiments. A representative example of dynamic equilibrium conditions achieved during high strain rate tensile tests is presented in Fig.7 Additional dynamic experiments were conducted at higher strain rates $\left(\sim 2000 \mathrm{~s}^{-1}\right)$ in order to assess the rate dependent behaviour of the three alloys across a wider spectrum of dynamic conditions. Fig.8 summarises the responses of the three materials at the various nominal strain rates imposed during the experiments. Specifically, the average yield stress of Ti0.7Al4V (Fig. 8 a) increases from about $584 \mathrm{MPa}$ under quasi-static loading, to $780 \mathrm{MPa}$ at $250 \mathrm{~s}^{-1}$ and to $900 \mathrm{MPa}$ at $2400 \mathrm{~s}^{-1}$. The average engineering strain to failure decreases slightly from $29 \%$ to approximately $27 \%$ from quasi static to dynamic conditions. The average yield stress of Ti1Al4V (Fig 8 b) rises from $522 \mathrm{MPa}$ under quasi-static loading to $700 \mathrm{MPa}$ at $250 \mathrm{~s}^{-1}$ and to $760 \mathrm{MPa}$ at $2500 \mathrm{~s}^{-1}$. Also, in this case the average engineering strain to failure decreases slightly, from $31 \%$ during quasi static loading to approximately $29 \%$ in dynamic conditions. The average yield stress of Ti3A12.5V (Fig 8 c) increases from $587 \mathrm{MPa}$ under quasi-static loading to $720 \mathrm{MPa}$ at $250 \mathrm{~s}^{-1}$ and to 850 $\mathrm{MPa}$ at $1800 \mathrm{~s}^{-1}$. The strain to failure of this alloy remains substantially unchanged from quasi static to dynamic loading conditions. 


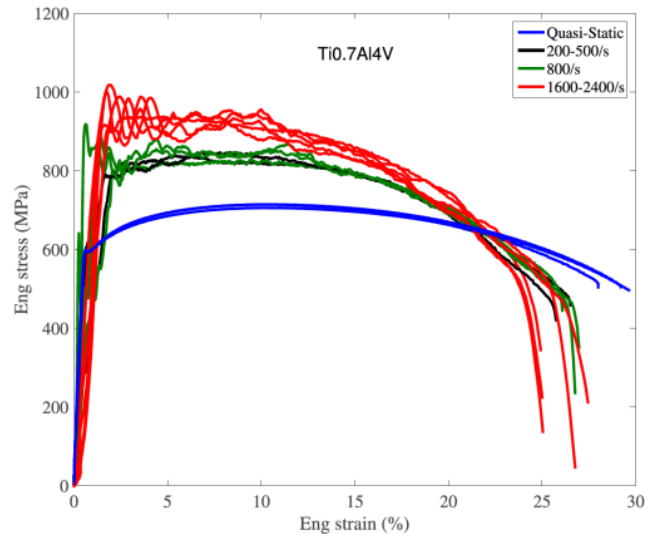

(a) Ti0.7Al4V

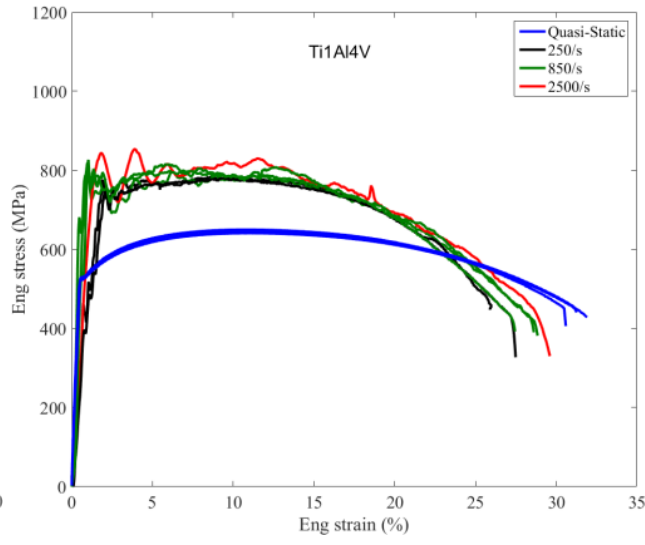

(b) Ti1Al4V

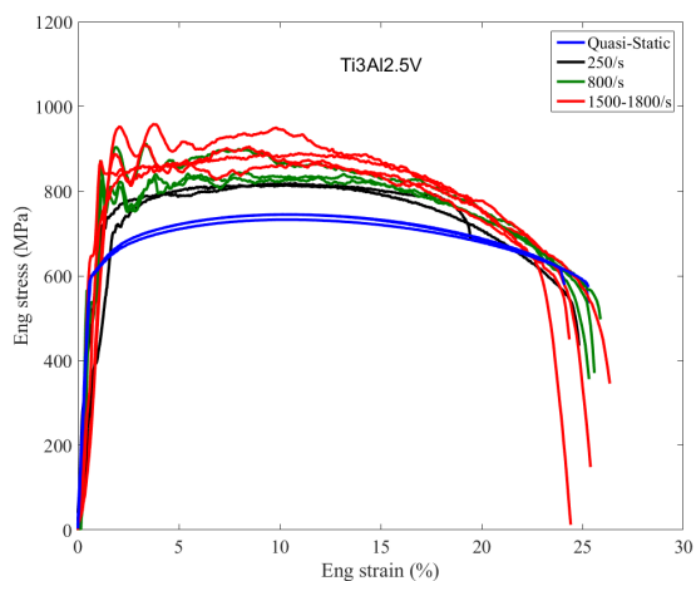

(c) Ti3Al2.5V

Fig.8 - Rate sensitivity of alloys Ti0.7Al4V (a), Ti1Al4V (b) and Ti3Al2.5V (c) - engineering stress strain curves measured at different nominal rates of strain.

It is noted that the nominal strain rate represents the volume average of the strain rate distribution over the entire gauge length of specimen. Beyond the onset of necking, strains cease to be uniform along the gauge length and localise around the necking area. As a consequence, the nominal strain rate underestimates the effective strain rate experienced by the material after strain localisation. This is particularly evident for ductile metal alloys. The effective strain rate can be determined experimentally as:

$$
\dot{\varepsilon}_{\text {true }}=\frac{d}{d t}\left[2 \cdot \ln \left(\frac{\emptyset_{0}}{\varnothing}\right)\right]
$$

Where $\emptyset_{0}$ and $\varnothing$ are the initial and current diameter of the minimum cross section of the specimen, measured by means of high speed photography. Fig.9 shows the evolution of the 
true strain rate during experiments conducted at nominal strain rates equal to $\sim 500-850 \mathrm{~s}^{-1}$ on the three alloys of interest for this work. The true strain rate increases to approximately 8000 $\mathrm{s}^{-1}$, about an order of magnitude higher than the nominal strain rate. This is consistent with the studies of Mirone [12] and Mirone et al. [24]. The evolution of current diameter and true strain rate during dynamic experiments constitute a measure for the suitability of the material models described in section 4 .

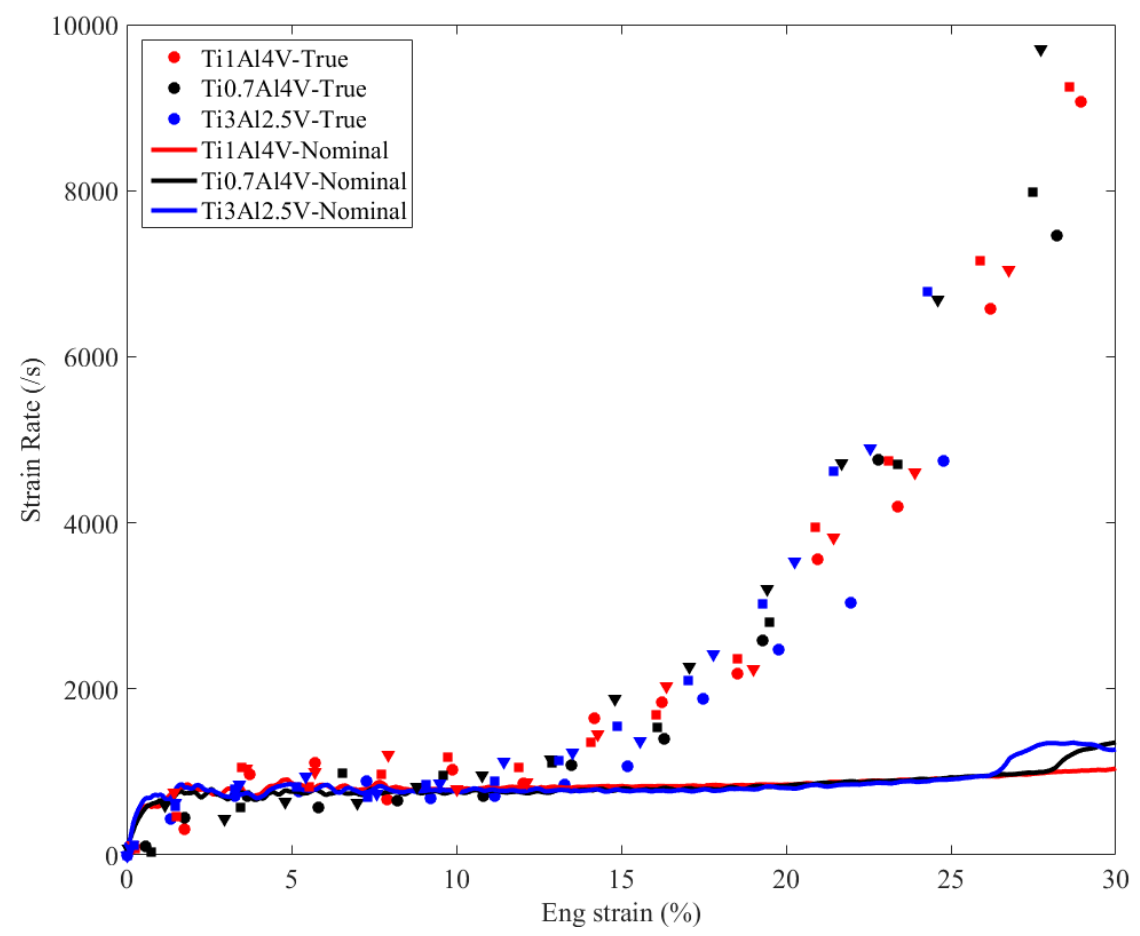

Fig.9 - Evolution of the true strain rate during experiments conducted at nominal strain rates between $500 \mathrm{~s}^{-1}$ and $850 \mathrm{~s}^{-1}$ on Ti0.7Al4V, Ti1Al4V, Ti3Al2.5V alloys.

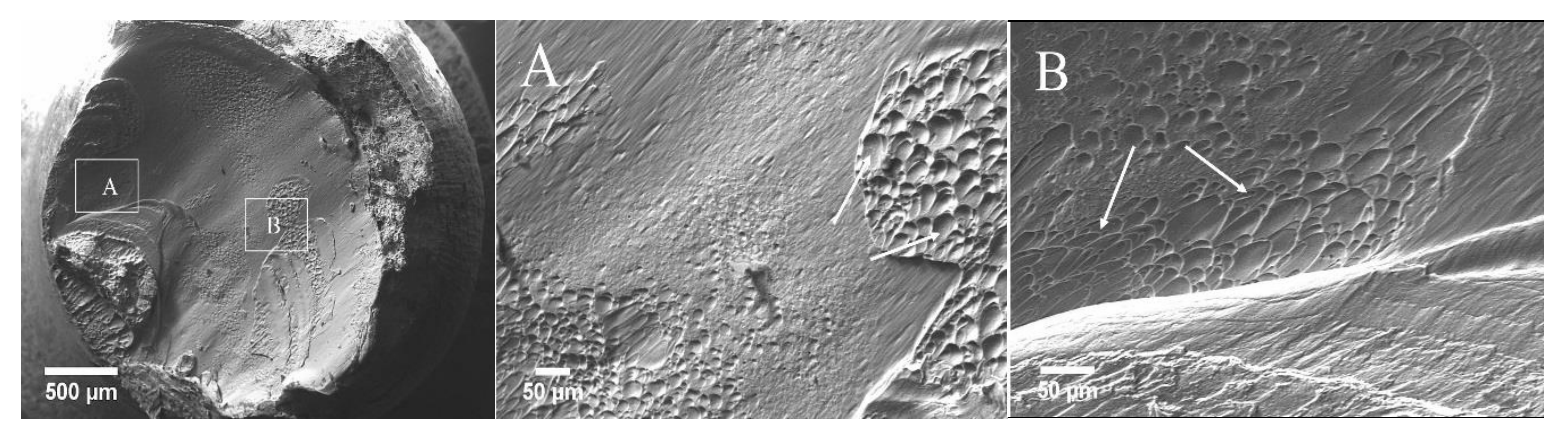

(a) Ti0.7Al4V 


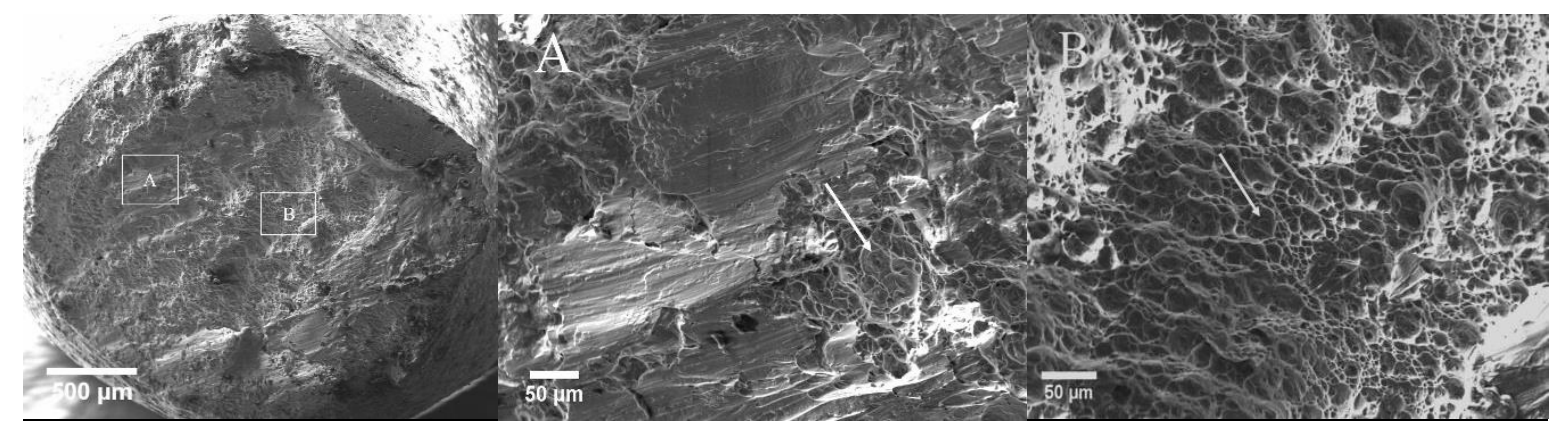

(b) Ti1Al4V

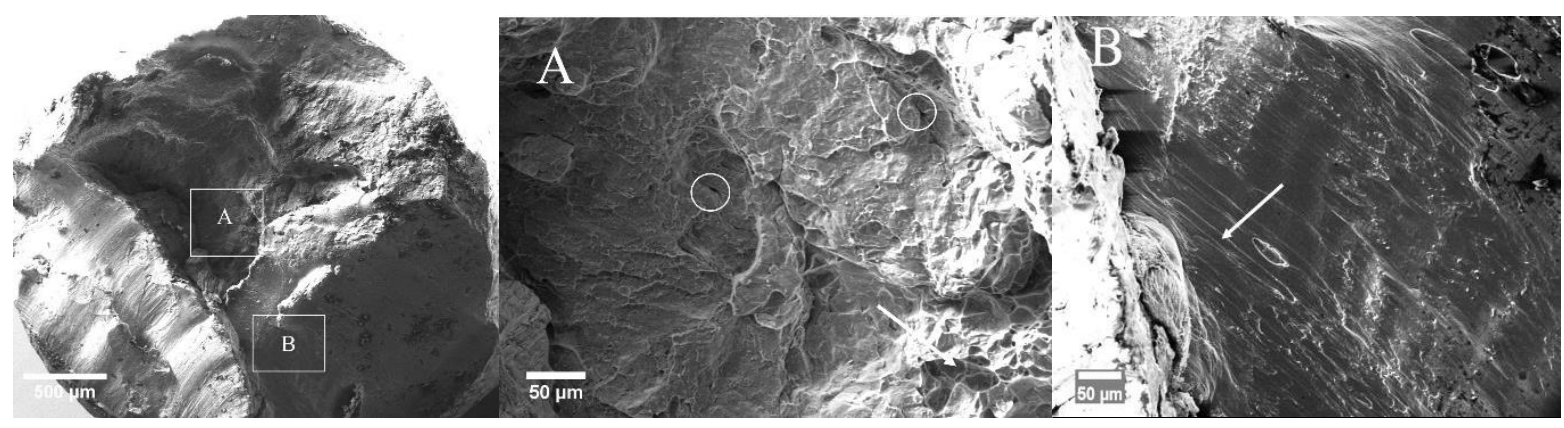

(c) Ti3Al2.5V

Fig.10 Representative fracture morphologies of specimens tested under dynamic tensile loading at nominal strain rate $\sim 500-850 \mathrm{~s}^{-1}$. Shear dimples are arrowed. Secondary cracks are circled.

The fracture surfaces of post mortem tensile specimens were examined using a Carl Zeiss Evo LS15 VP-Scanning Electron Microscope. Micrographs of the fracture morphology of the three titanium alloys under investigation are shown in Fig.10. Specifically, the Ti0.7Al4V specimen examined presents a fracture surface aligned with maximum shear stress plane, in which the relatively smooth and smeared regions, and the shear dimple areas coexist (Fig. 10a). The fracture morphology of the Ti1A14V specimen exhibits a cup-cone fracture with a prominent shear lip (Fig. 10b). Region A presents several smooth areas comprising of severely elongated dimples $[25,26]$, Region B is characterized by a high density of dimples. The fracture surface feature of the Ti3Al2.5V specimen presents a flat rough region and a small shear lip (Fig. 10c). The rough region (region $\mathrm{A}$ ) is composed of a mixture of dimples, large voids and secondary cracks with cleavage-like facets, while the shear lip (region B) presents elongated dimples and a smeared surface. 


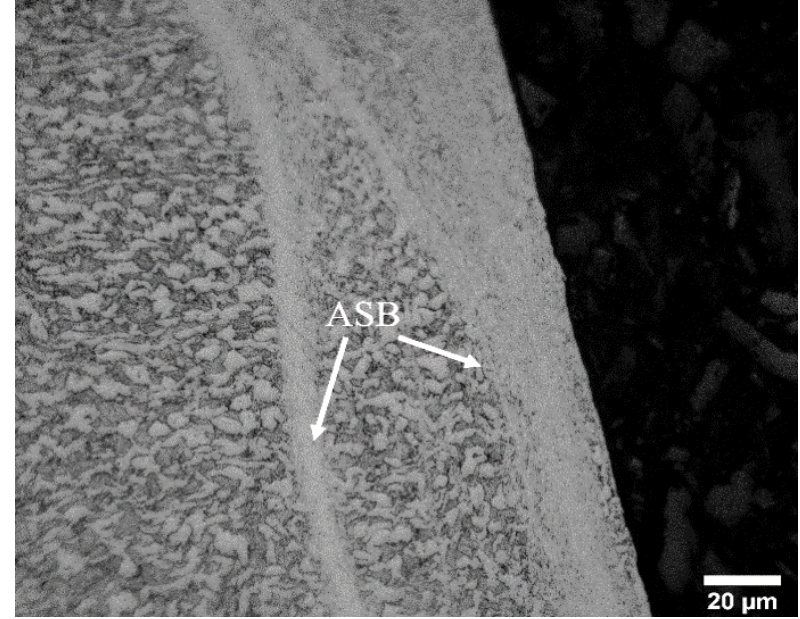

(a) $\mathrm{Ti} 0.7 \mathrm{Al} 4 \mathrm{~V}$

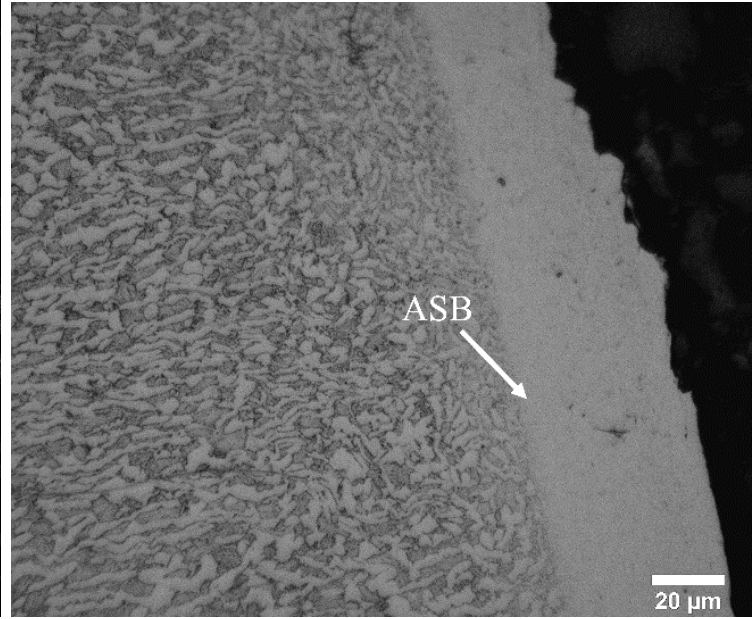

(b) Ti1Al4V

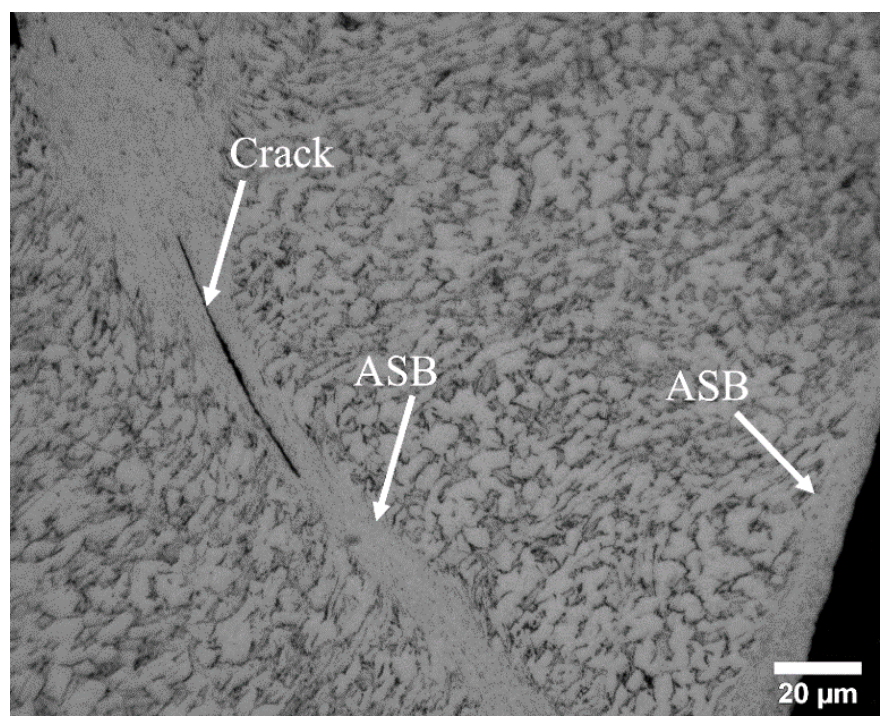

(c) $\mathrm{Ti} 3 \mathrm{Al} 2.5 \mathrm{~V}$

Fig.11 Optical micrographs of tensile specimens after failure - microstructures of Ti0.7A14V (a), Ti1Al4V (b), Ti3Al2.5V (c).

The post mortem microstructures of specimens deformed at nominal strain rates in the region of 500-850 s-1 were analyzed by means of optical microscopy (Fig.11). Adiabatic shear bands (ASB), typical of dynamic ductile failure, are observed in all investigated titanium alloys. Fig.11(a) and Fig.11(c) show two shear bands (arrowed) in Ti0.7Al4V and Ti3Al2.5V respectively. The appearance of a crack within the shear band is evident in Ti3Al2.5V.

\section{Constitutive Modelling and Numerical Simulations}




\subsection{Constitutive Models Description}

Two phenomenological models, Johnson-Cook (JC) model [27] and Khan-Huang-Liang (KHL)[28, 29] model, are employed to describe the dynamic tensile behaviour of the three titanium alloys studied. The classic JC constitutive model [27] for the description of metals subjected to large strains, high strain rates and high temperatures, has been used extensively due to its simplicity and the availability of parameters for various materials of interest. The KHL constitutive model $[28,29]$ has typically been used to describe the strain rate and temperature dependent mechanical behaviour of titanium alloys.

The flow stress in JC model is given by multiplicative effects as follows:

$$
\sigma=\left(A+B \varepsilon_{p}^{n}\right)\left(1+C \ln \left(\frac{\dot{\varepsilon}}{\dot{\varepsilon}_{0}}\right)\right)\left(1-\left(\frac{T-T_{r}}{T_{m}-T_{r}}\right)^{m}\right)
$$

where $\sigma$ is the stress, $\varepsilon_{P}$ is the plastic strain, $\mathrm{A}, \mathrm{B}, \mathrm{C}, \mathrm{n}$ and $\mathrm{m}$ are material parameters. $\dot{\varepsilon}$ is the plastic strain rate and $\dot{\varepsilon_{0}}$ is a reference strain rate. $T_{r}$ is a reference temperature, $T_{m}$ is the melting temperature for the material of interest and $\mathrm{T}$ is the current temperature.

The flow stress in KHL model is given by:

$$
\sigma=\left[A+B\left(1-\frac{\ln \dot{\varepsilon}}{\ln \mathrm{D}_{0}^{\mathrm{P}}}\right)^{n_{1}}\left(\varepsilon_{P}\right)^{n_{0}}\right]\left(\frac{\dot{\varepsilon}}{\dot{\varepsilon_{0}}}\right)^{C}\left(\frac{T_{m}-T}{T_{m}-T_{r}}\right)^{m}
$$

where $\sigma$ is the stress and $\varepsilon_{P}$ is the plastic strain. $T_{m}, T$ and $T_{r}$ are melting, current and reference temperatures respectively. $D_{0}^{P}$ is an arbitrarily chosen upper bound strain rate and $\dot{\varepsilon_{0}}$ is a reference strain rate. $\mathrm{A}, \mathrm{B}, n_{1}, n_{0}, C$ and $\mathrm{m}$ are material constants.

The dynamic deformation of titanium alloys is associated with a temperature rise due to the conversion of mechanical energy into heat. The integration of the transient stress-thermal balance equation, assuming adiabatic conditions, while neglecting thermoelastic couplings, results in:

$$
\beta_{\text {int }} \int_{0}^{\alpha} \sigma d \varepsilon_{\mathrm{p}}=\rho c_{p} \Delta T
$$

where $\rho$ is the material density, $c_{p}$ is the specific heat capacity and $\Delta T$ is the temperature rise. $\beta_{\text {int }}$ is the integral Taylor-Quinney factor[30], which expresses the fraction of the plastic strain energy density converted into heat.

\subsection{Constants Calibrations}

The experimental static and dynamic average true stress-true plastic strain curves before the onset necking are shown in Fig.12. Due to the negligible temperature rise before necking [6, $10,31]$, thermal effects are herein not considered when calibrating the constants in the JC and 
KHL models. The method used for the calibration of the models constants is illustrated below by taking Ti1Al4V as example.

\subsubsection{Constants in JC Model}

The reference strain rate $\dot{\varepsilon_{0}}$ is chosen as $\sim 0.00085 \mathrm{~s}^{-1}$, corresponding to the strain rate imposed during quasi static experiments At strain rate equal to $\dot{\varepsilon}_{0}$ and at room temperature, Eq. (4) reduces to $\sigma=A+B\left(\varepsilon_{P}\right)^{n}$. The average quasi-static curve at $0.00085 \mathrm{~s}^{-1}$ is used to determine the parameters A, B and $\mathrm{n}$ by using a simple least-squares approach through the curve fitting tool available in MATLAB. Here, for Ti1Al4V, A = 522 MPa, B =764 MPa and $n=0.566$.

Since the temperature rise before necking is modest $[6,10,31]$, thermal softening effect is not taken into account. The coefficient $\mathrm{C}$ is determined by best fitting the average dynamic experimental stress-strain curves obtained at $250 \mathrm{~s}^{-1}, 850 \mathrm{~s}^{-1}$ and $2500 \mathrm{~s}^{-1}$ with the JC model adopting the above reported static material parameters. The coefficient $\mathrm{C}=0.0205$ is determined as the dynamic stress amplification value. The calibrated JC constitutive equation for Ti1Al4V is therefore as follows,

$$
\sigma=\left(522+764 \varepsilon_{\mathrm{p}}^{0.566}\right)\left(1+0.0205 \ln \left(\frac{\dot{\varepsilon}}{\dot{\varepsilon}_{0}}\right)\right)
$$

The Johnson Cook parameters for alloys Ti0.7Al4V and Ti3Al2.5V are obtained following the same procedure and reported in Table 5.

\subsubsection{Constants in KHL Model}

The original KHL model $[28,29]$ is here slightly adjusted by using a normalized strain rate for the hardening part. The present KHL model is as follows,

$$
\sigma=\left[A+B\left(1-\frac{\ln \left(\frac{\dot{\varepsilon}}{\varepsilon_{0}}\right)}{\ln \mathrm{D}_{0}^{\mathrm{P}}}\right)^{n_{1}}\left(\varepsilon_{P}\right)^{n_{0}}\right]\left(\frac{\dot{\varepsilon}}{\dot{\varepsilon}_{0}}\right)^{C}\left(\frac{T_{m}-T}{T_{m}-T_{r}}\right)^{m}
$$

At the reference strain rate $0.00085 \mathrm{~s}^{-1}$ and room temperature, Eq. (8) reduces to $\sigma=A+$ $B\left(\varepsilon_{P}\right)^{n_{0}}$. The parameters $\mathrm{A}, \mathrm{B}, n_{0}$ are determined interpolating the average quasi-static curve measured at $0.00085 \mathrm{~s}^{-1}$ (Fig. 12). The constant $\mathrm{A}$ is the static yield stress. For Ti1A14V, $\mathrm{A}=$ $522 \mathrm{MPa}, \mathrm{B}=764 \mathrm{MPa}$ and $n_{0}=0.566$.

When $\varepsilon_{P}=0$, at different strain rates and room temperature, Eq. (8) reduces to $\sigma=\mathrm{A}\left(\frac{\dot{\varepsilon}}{\dot{\varepsilon}_{0}}\right)^{C}$. The parameter $\mathrm{C}=0.0230$ is determined interpolating the yield stress at difference rates. Once $\mathrm{A}$, $\mathrm{B}, n_{0}, \mathrm{C}$ are determined an arbitrary upper bound strain rate $\mathrm{D}_{0}^{\mathrm{P}}$ is chosen $\left(\mathrm{D}_{0}^{\mathrm{P}}=10^{22} \mathrm{~s}^{-1}\right)$. The parameter $\mathrm{n}_{1}$ is then calculated interpolating the stress-strain data measured at strain rates 
larger than the reference value $\dot{\varepsilon}_{0}$, obtaining an average value of $n_{1}=2.300$. The calibrated KHL constitutive equation for Ti1 Al4V is as follows,

$$
\sigma=\left[522+764\left(1-\frac{\ln \left(\frac{\dot{\varepsilon}}{\varepsilon_{0}}\right)}{\ln \mathrm{D}_{0}^{\mathrm{P}}}\right)^{2.300}\left(\varepsilon_{P}\right)^{0.566}\right]\left(\frac{\dot{\varepsilon}}{\varepsilon_{0}}\right)^{0.0230}
$$

The KHL model parameters for alloys Ti0.7A14V and Ti3A12.5V are obtained following the same procedure. A comparison between the experimental stress-strain curves and the calibrated model descriptions for the three titanium alloys is given in Fig. 12. Table 5 shows the parameters for the JC and KHL models, together with other material properties adopted in the numerical simulations. In the next section, the calibrated constitutive models will be compared by means of finite element analysis.

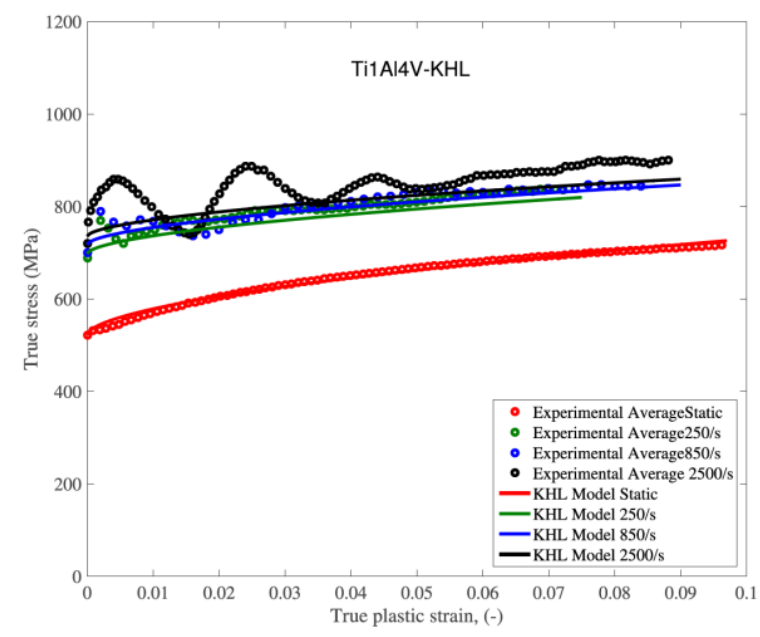

(a)-1

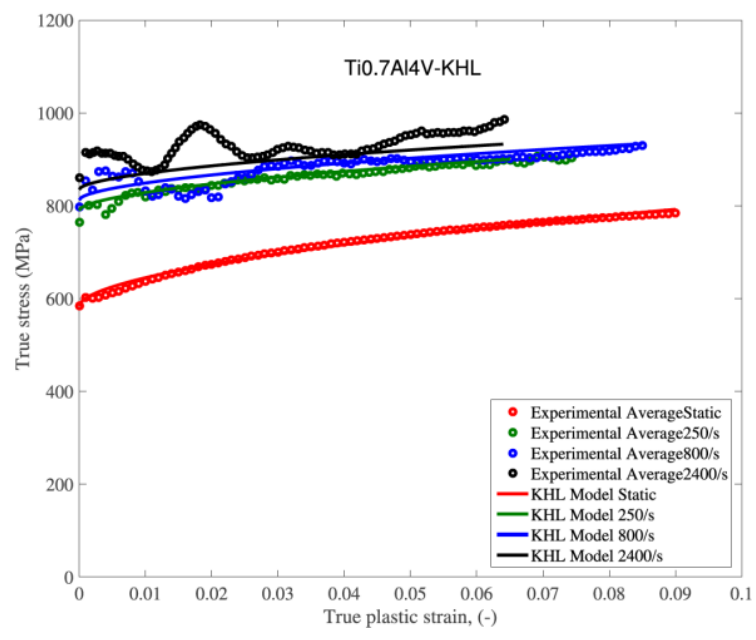

(b)-1

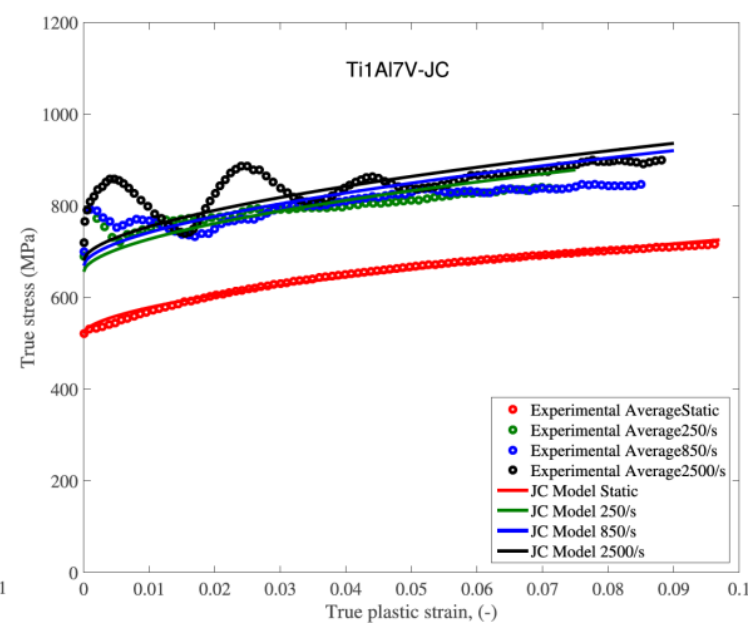

(a) -2

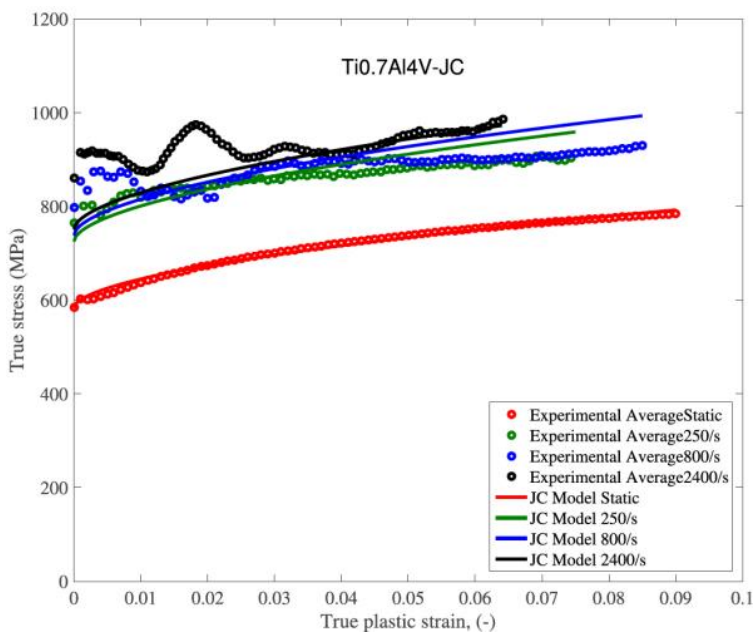

(b)-2 


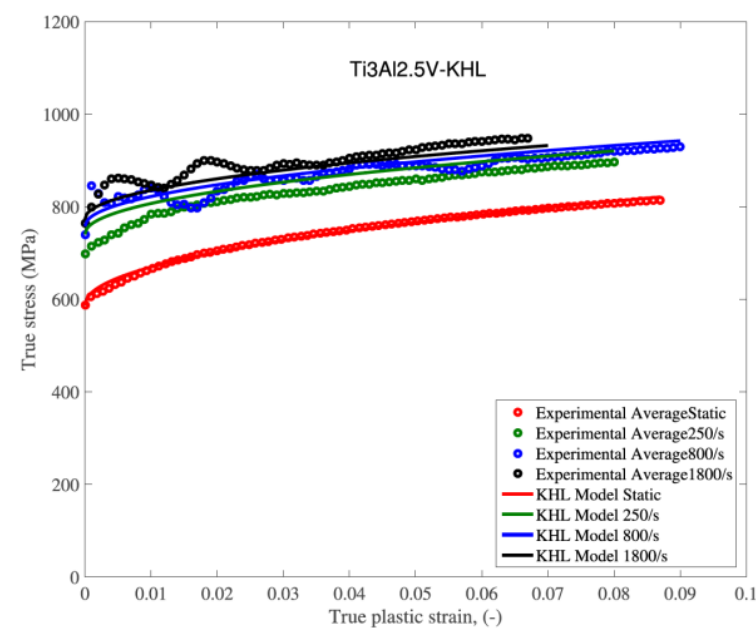

(c)-1

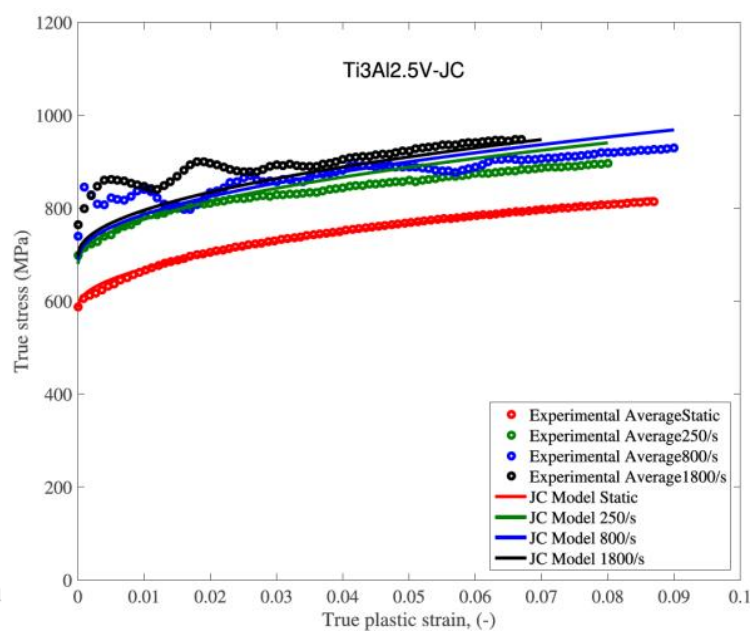

(c)-2

Fig.12 Comparison between constitutive models and experimental data for the three titanium alloys investigated.

Table 5. Summary of the JC and KHL constitutive model parameters

\begin{tabular}{cccccccccc}
\hline \multirow{3}{*}{ Material } & \multicolumn{3}{c}{ Johnson-Cook (JC) Constitutive } & Model & \multicolumn{5}{c}{ Khan-Huang-Liang (KHL) Constitutive Model } \\
& A (MPa) & B (MPa) & C & n & A (MPa) & B (MPa) & C & $n_{0}$ & $n_{1}$ \\
Ti0.7Al4V & 522 & 764 & 0.0205 & 0.566 & 522 & 764 & 0.0230 & 0.566 & 2.300 \\
Ti1Al4V & 584 & 802 & 0.0192 & 0.560 & 584 & 802 & 0.0240 & 0.560 & 2.650 \\
Ti3Al2.5V & 587 & 756 & 0.0126 & 0.480 & 587 & 756 & 0.0185 & 0.480 & 1.600 \\
\hline
\end{tabular}

\subsection{Numerical Simulations:}

A series of finite element simulations are carried out by using the explicit version of the finite element code ABAQUS [32] to assess the accuracy of the two models with respect to the measured experimental results.

\subsubsection{Finite Element Model:}

The symmetry of the problem allows for only half of the tensile specimen to be modelled, reducing the computational time. The dimensions of the simulated specimen reflect those of the specimens employed for the experiments. The sample threads are not modelled. The specimen is meshed with 3D linear hexahedral elements of type C3D8R, with reduced integration and hourglass control. The mesh size in the gage section is chosen as $0.2 \mathrm{~mm}$ consistently with the selected subset size employed for digital image correlation analyses. The 
experimental measured input and output velocities from Hopkinson bar analysis are applied as the boundary conditions at the two faces of the tensile specimen, for the numerical simulations to reflect accurately dynamic loading test conditions.

The constants in the material models are obtained according to the procedures described above. The KHL model is implemented into the finite element code by means of a VUMAT user subroutine using a classical von Mises yield criterion. The stress tensor is updated with the radial return algorithm $[33,34]$ and the Newton-Raphson procedure is used to solve the value of the equivalent plastic strain increment. Note that throughout the numerical work presented here, no damage and no temperature induced thermal strain are introduced to the simulations. The parameters of JC and KHL models in the finite element simulations are given in Table 5. Typical values of Young modulus (110 GPa), Poisson ratio $(0.33)$, density $\left(4500 \mathrm{~kg} / \mathrm{m}^{3}\right)$, specific heat $(526 \mathrm{~J} / \mathrm{kg} \cdot \mathrm{K})$, melting temperature $\left(1705 \mathrm{C}^{\circ}\right)[5,17,28]$ and Taylor-Quinney factor $(0.65)[9,10,30]$ were used for the three investigated titanium alloys. The temperature dependence coefficients were set to $m=1.0[6,28,35-37]$ in JC model and $m=1.5[6,28,35]$ in KHL model.

\subsubsection{Simulation Results:}

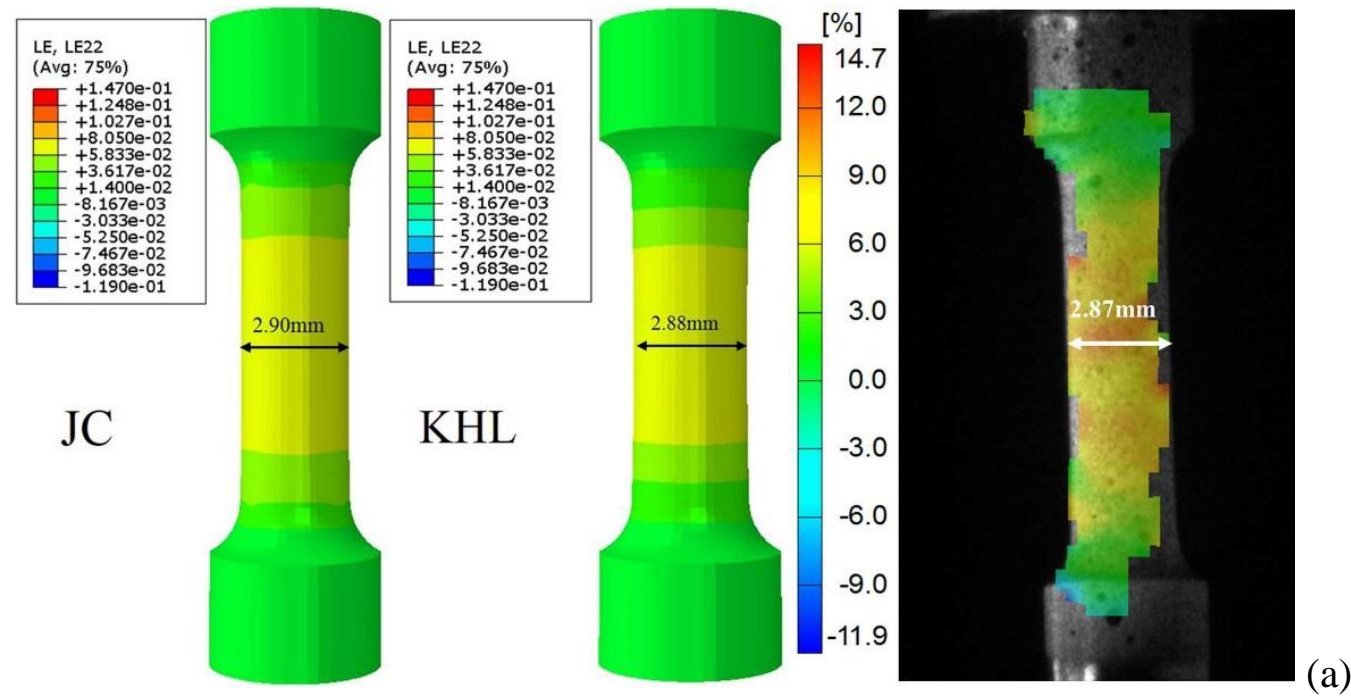




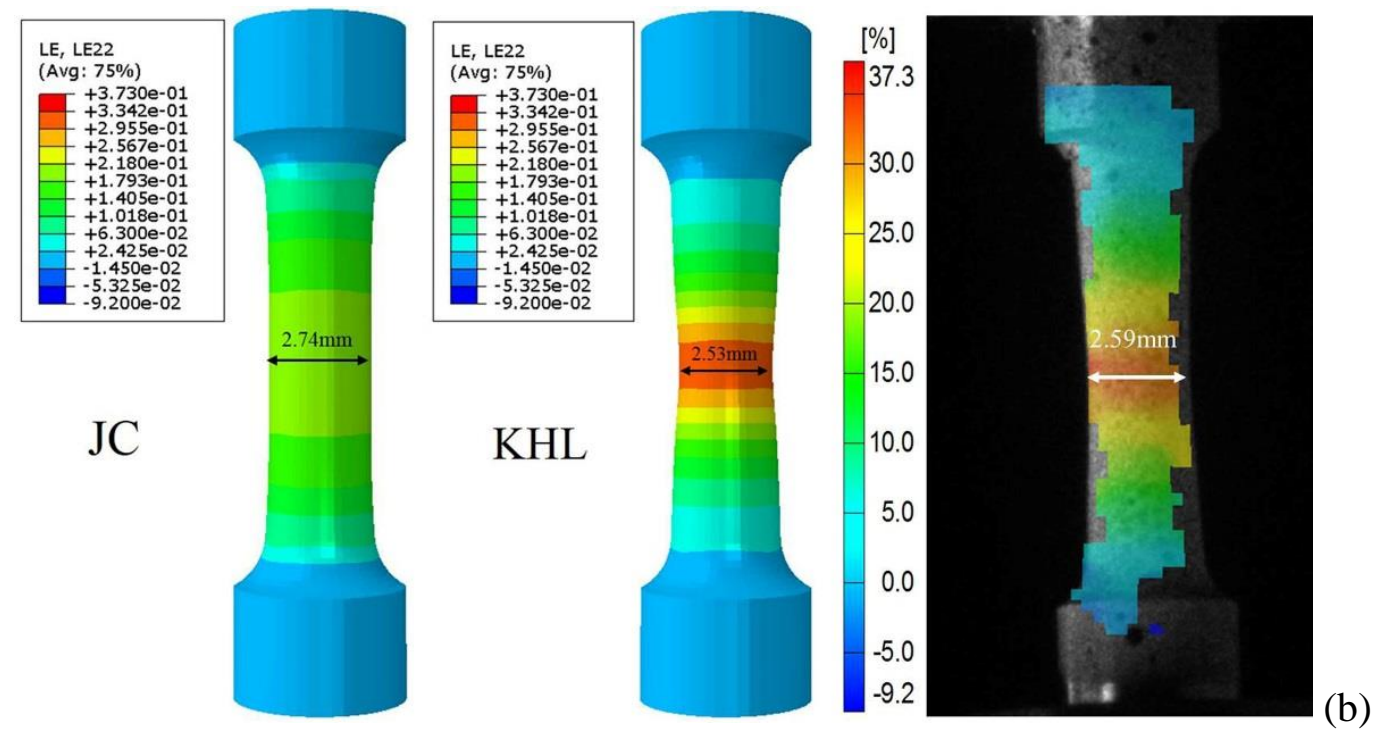

Fig.13 Axial strain field of a Ti1Al4V alloy specimen simulated using the JC and KHL models, together with the corresponding experimental measurements (right).

Fig 13 shows the deformed specimens corresponding to engineering strains before (a) and beyond the onset of necking (b). The numerical axial strain field distributions and the deformation shape from simulations are compared with DIC results. At these stages, the strain field and the current minimum diameter from the KHL model present good agreement with the experimental images results. On the contrary the JC model underestimates the maximum strain value in the specimen. In Fig.13 (b), the current minimum diameter predicted by the JC model is $2.74 \mathrm{~mm}$, which is significantly larger than that obtained from the image analysis. 


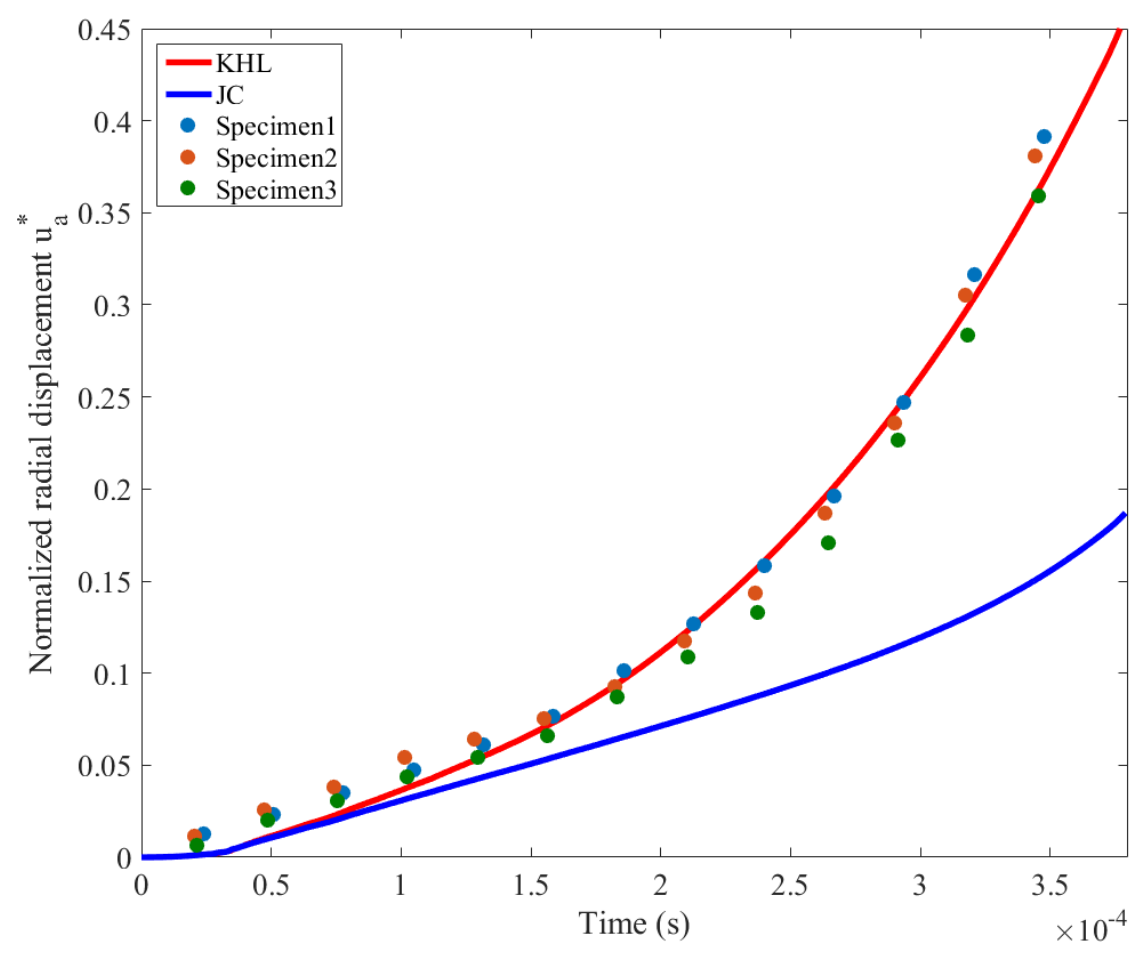

Fig. 14 Comparison between experimental and numerical normalized radial displacement histories of the central cross-section of the neck, $u_{a}^{*}=\frac{2 u_{a}}{\emptyset_{0}-2 u_{a}}$.

To illustrate the cross-section evolution, Fig.14 compares the experimental and numerical histories of the normalized radial displacement at the necking location $u_{a}^{*}=\frac{2 u_{a}}{\emptyset_{0}-2 u_{a}}$ [38]. Here, $u_{a}$ is the radial displacement of the central cross-section of the neck, measured at the free surface of the specimen, and $\emptyset_{0}$ is the original diameter of the specimen. This normalized value is herein used to represent the necking evolution. The normalized radial displacement evolution predicted by the KHL model matches very closely the experimental data. Conversely, the normalized radial displacement evolution from the JC model exhibits apparent divergence and fails to predict the parabolic curve pattern of the experimental data. 


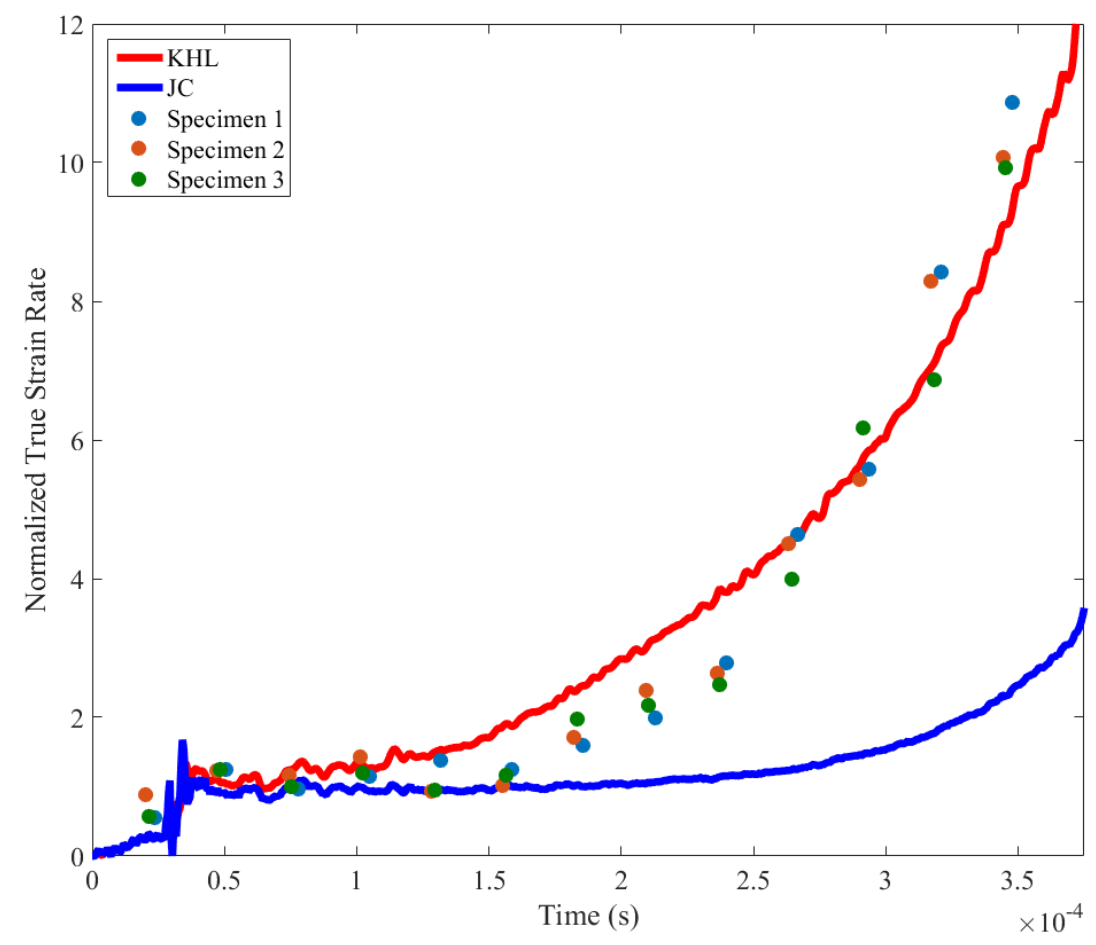

Fig.15 Comparison between experimental and numerical normalized true strain rate histories.

Fig.15 presents the normalized true strain rate, the true strain rate normalized by the measured average nominal strain rate, as a function of time for Ti1 Al4V specimens. The effective strain rate is influenced by necking occurring during dynamic tensile deformation and, therefore, is substantially different from the nominal applied strain rate, reaching values up to one order of magnitude higher compared to the latter. It is evident that the evolution of the normalized true strain rate obtained using the KHL model follows closely the experimental data, whilst the JC model fails to reflect the true strain rate upsurge measured beyond necking.

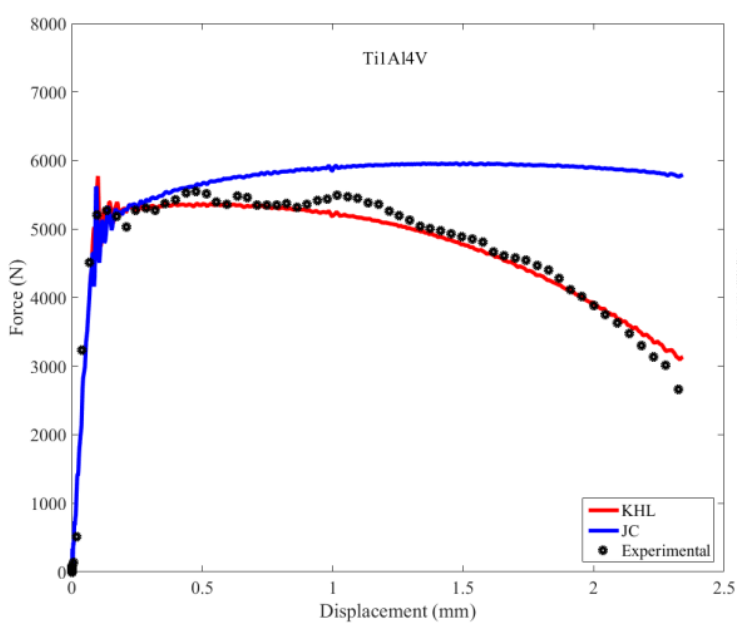

(a)

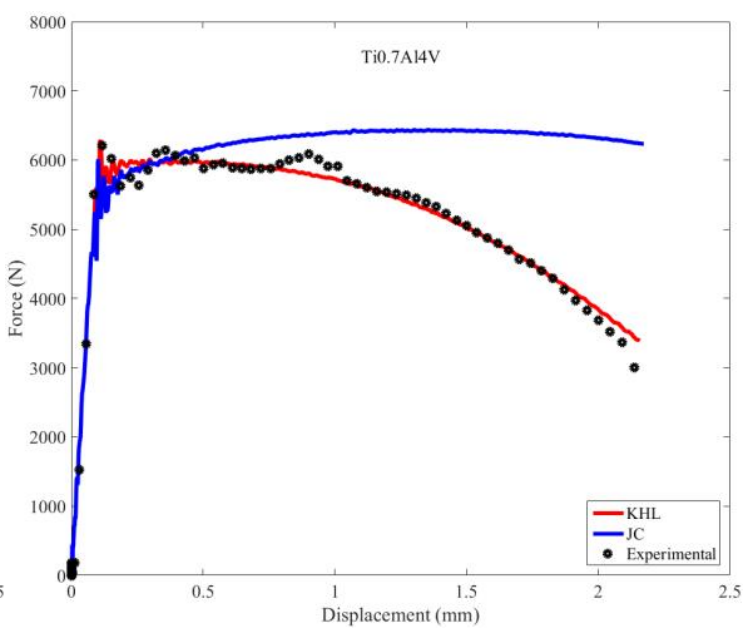

(b) 


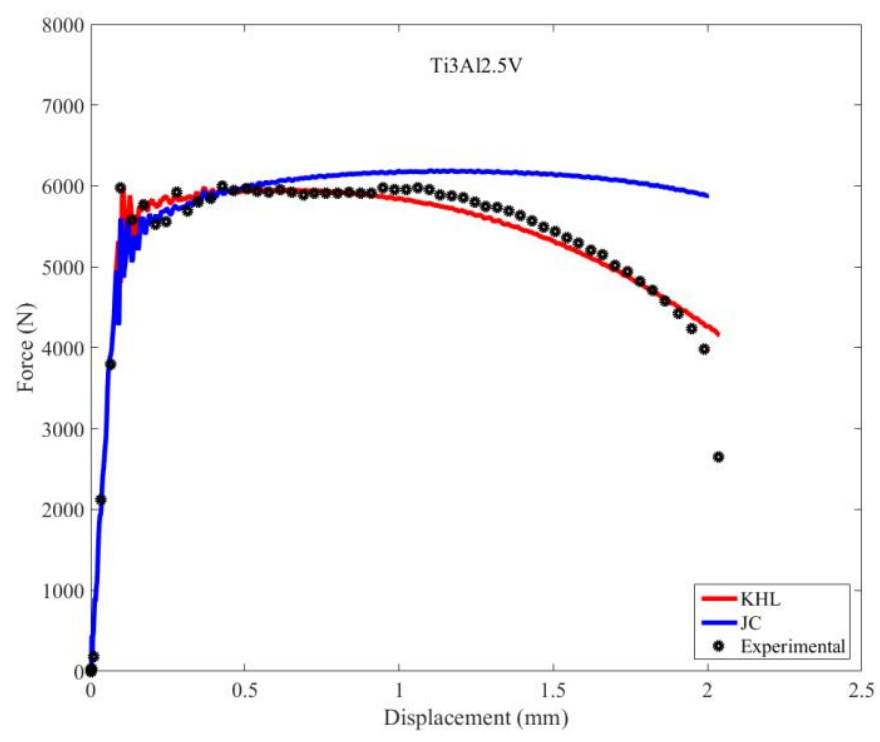

(c)

Fig. 16 Comparison between the force-relative displacement curves obtained from the JC and KHL models and the corresponding experimental data.

Fig. 16 shows the comparison between the experimental and numerical force-relative displacement curves at a strain rate of $\sim 850 \mathrm{~s}^{-1}$. The purpose of this procedure is to assess if the selected constitutive models can reproduce the experimental force-displacement measured experimentally. The numerical force is the total reaction force from the bottom face of the specimen, while the numerical displacement is the relative displacement between the top and bottom sides of the specimen. The force-displacement relationships obtained from the JC model exhibit some degree of hardening not measured experimentally, while the numerical results from the KHL model and the experimental data are well matched, indicating the suitability of the KHL model in the prediction of the dynamic tensile response of the three titanium alloys under investigation. 


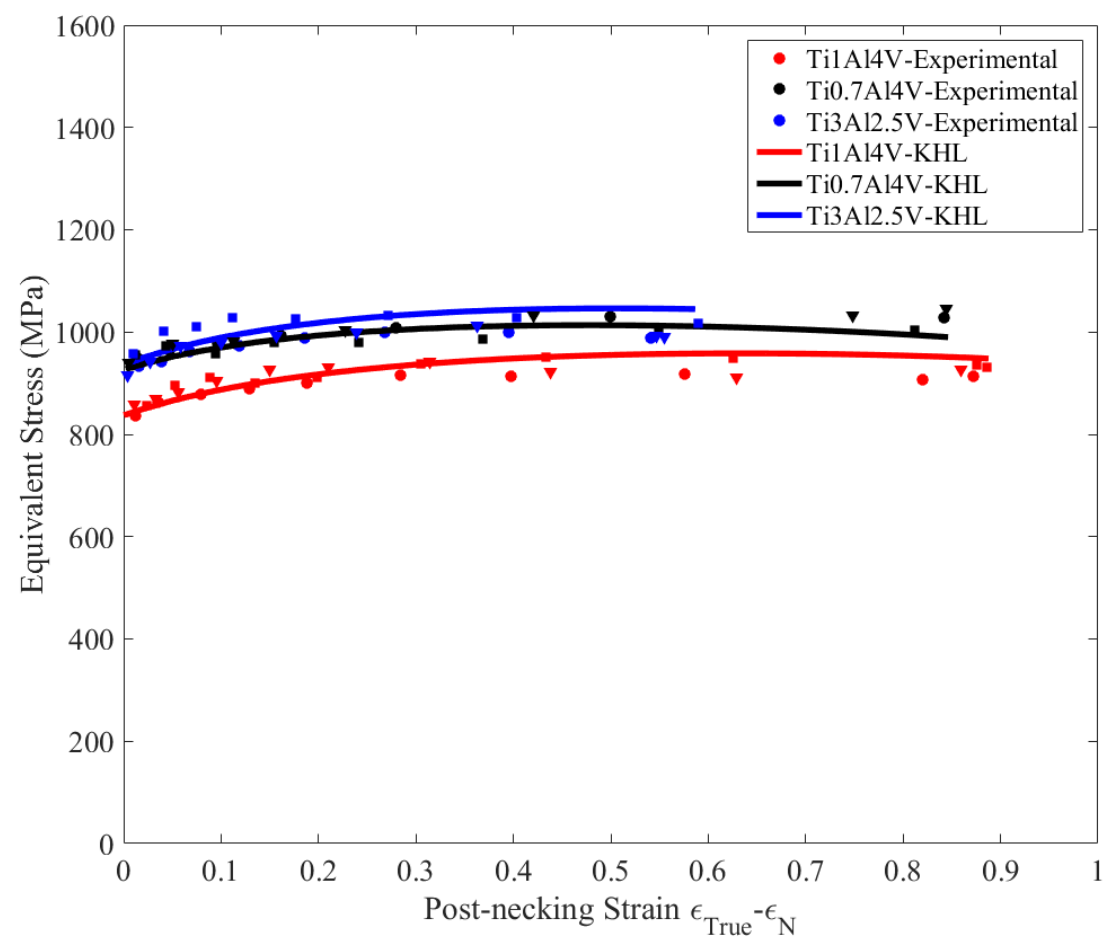

Fig.17 Comparison between the post-necking equivalent stress vs true strain from numerical simulations and the corresponding experimental curves obtained using the MLR correction.

Finally, the equivalent Von Mises stress from the KHL model are compared to the corresponding data obtained from the dynamic experiments. When necking occurs in a cylindrical specimen the central cross section of the neck is constrained by the adjacent cross sections. As a result, a triaxial stress state develops in the necking region [39].The determination of the equivalent Von Mises stress from the average axial true stress (Eq. 2) has received considerable attention in literature. The material-independent MLR [24, 40, 41] correction allows to convert the post-necking true stresses into the von Mises stresses all over the post-necking strain range. Specifically:

$\sigma_{\text {eq }}\left(\varepsilon_{\text {eq }}\right)=\sigma_{\text {true }}\left(\varepsilon_{\text {true }}\right) \cdot \operatorname{MLR}\left(\varepsilon_{\text {eq }}-\varepsilon_{\mathrm{N}}\right)$

$\operatorname{MLR}\left(\varepsilon_{\text {eq }}-\varepsilon_{\mathrm{N}}\right)=1-0.6058 \cdot\left(\varepsilon_{e q}-\varepsilon_{N}\right)^{2}+0.6317 \cdot\left(\varepsilon_{e q}-\varepsilon_{N}\right)^{3}-0.2107 \cdot\left(\varepsilon_{e q}-\varepsilon_{N}\right)^{4}$

Here, $\varepsilon_{\mathrm{N}}$ is the necking initiation true strain, $\sigma_{\mathrm{eq}}$ and $\varepsilon_{\mathrm{eq}}$ are the current Mises stress and equivalent strain averaged over the current minimum cross section, the latter being approximately equal to $\varepsilon_{\text {true }}[13,41]$. It is therefore possible, using the MLR correction, to determine the equivalent stress from the experimental true stress and true strain data. Fig.17 compares the equivalent stress data obtained experimentally using the MLR correction and the equivalent stress results obtained numerically from the KHL model. The numerical equivalent 
stress and true axial strain values are the averages computed from the elements located at the current central cross-section of the neck. It is evident that the post necking experimental data from MLR correction and the analogous numerical simulation results exhibit good agreement.

\section{Discussion}

The components of a commercial jet engine must be designed in order to ensure its integrity in case of failure and subsequent release of any of its parts during operation. As a result, the development of novel titanium alloys for impact containment applications requires the experimental characterisation and understanding of their dynamic behaviour. This paper reports and analyses the tensile response of three novel titanium alloys at quasi static, intermediate and high strain rates. The three titanium alloys exhibit apparent strain rate sensitivity and different mechanical responses in terms of flow stress, strain hardening and ductility. Ti1Al4V is characterised by the lowest flow stress and the largest strain to failure among the three alloys. Ti3 Al2.5V presents higher flow stress but lower ductility when compared to TilAl4V while Ti0.7Al4V presents similar flow stress but larger engineering failure strain with respect to $\mathrm{Ti} 3 \mathrm{Al} 2.5 \mathrm{~V}$. Correspondingly, the analyses of the fracture morphology for Ti1 Al4V shows a cup-cone fracture with a prominent shear lip region revealing a ductile fracture. Ti0.7A14V shows a fracture surface aligned with maximum shear stress plane. The fracture surface of Ti3Al2.5V presents a flat rough region and a small shear lip. The three titanium alloys fail by adiabatic shear bands, typical characteristics of ductile failure, when loaded dynamically.

Both JC and KHL constitutive models are employed to describe the strain and strain-rate, dependent responses of the three alloys. The constitutive model parameters in Table 5 are calibrated based on the experimental data and the models suitability is evaluated by means of numerical simulations conducted using the commercial finite element code ABAQUS.

The strain field, current diameter and true strain rate evolution from experiments are compared with the results obtained using the JC and KHL models. The results obtained using the JC model differ noticeably with respect to the experimental data, while the simulation results from the KHL model match these closely. In particular, the measured effective strain rate beyond necking is substantially different from the nominal applied strain rate, reaching values up to one order of magnitude higher than the latter in ductile alloys, in agreement with Mirone [13]. The effective strain rate can be controlled by the striker velocity only up to necking. The evolution of the normalized true strain rate from the KHL model matches accurately the 
experimental data, while the JC model fails to predict the apparent strain rate upsurge occurring after necking. This is due to the fact that, while the parameters related to the quasi static experimental data are identical for the two models, the parameter $n_{1}$, incorporated into the strain hardening term of the KHL model, allows for the latter to be rate dependent. As a result the KHL model is able to reproduce the decrease in work hardening with increasing strain rates featured in the dynamic behaviour of the investigated ductile alloys. Conversely the JC model, in which the work-hardening increases with increasing strain rate [28, 42], appears to be unsuitable to model the work-hardening behaviour of the three titanium alloys of interest.

The numerical work presented aims at comparing the two constitutive models and validate their parameters. Damage evolution and failure criterion are not introduced at present. The appearance and growth of voids and corresponding damage may occur during dynamic tensile necking [43]. Appropriate failure criterion and damage evolution models [6, 44] are required to describe the ductile fracture in titanium alloys. These will be addressed in future research. In addition, the dynamic response of titanium alloys subjected to impact loading is also influenced by the environmental temperature and by the temperature evolution in the specimen itself [10]. Future research will aim at studying the temperature dependent dynamic behaviour of the titanium alloys herein investigated.

\section{Conclusions}

This paper investigates the dynamic response of three novel titanium alloys, Ti0.7Al4V, Ti1Al4V and Ti3Al2.5V, conceived for impact containment applications. The experimental data and relevant constitutive model parameters provide useful information for the effective design of the above components. The main results are summarized as follows:

- The three titanium alloys exhibit noticeable strain rate sensitivity and different mechanical responses in terms of flow stress, strain hardening and ductility. Ti1 A14V is characterised by the lowest flow stress and highest ductility among the three alloys. Ti3A12.5V presents higher flow stress but lowest strain to failure while Ti0.7Al4V presents similar flow stress but larger engineering failure strain with respect to Ti3Al2.5V.

- The measured effective strain rate during dynamic experiments increases to values up to one order of magnitude higher than the imposed nominal strain rate. The microstructural characterization of the failure surfaces shows that the three titanium alloys investigated fail by adiabatic shear banding already at intermediate strain rates 
$(\sim 500-850 \mathrm{~s}-1)$ emphasising the necessity to examine rigorously strain rate localization for the design of structures subjected to impact loading.

- The JC and KHL constitutive models are employed to describe the strain and strainrate, dependent responses of the three alloys. It is found that the KHL model predicts the mechanical response, strain field, cross section area evolutions and macroscopic force-displacement responses with better agreement than the JC model, indicating the suitability of the KHL model for the prediction of the dynamic tensile response of the investigated titanium alloys.

\section{Acknowledgements:}

The authors would like to thank Mr. Stuart Carter and Mr. Jeffrey Fullerton for their assistance with fixture preparation and experimental setup, Dr David Townsend for enlightening conversations and useful information and Mrs. Karen Bamford for helping everyone stay focused. The provision of materials and supporting information from TIMET UK is gratefully acknowledged.

\section{Data availability}

The raw/processed data required to reproduce these findings cannot be shared at this time due to technical or time limitations.

\section{References}

[1] H. Kolsky, Proceedings of the Physical Society. Section B, 62 (1949) 676.

[2] J. Harding, E. Wood, J. Campbell, Journal of Mechanical Engineering Science, 2 (1960) $88-96$.

[3] M.A. Meyers, G. Subhash, B.K. Kad, L. Prasad, Mechanics of Materials, 17 (1994) 175193.

[4] D. Chichili, K. Ramesh, K. Hemker, Acta materialia, 46 (1998) 1025-1043.

[5] S. Nemat-Nasser, W. Guo, J. Cheng, Acta materialia, 47 (1999) 3705-3720.

[6] D. Macdougall, J. Harding, J Mech Phys Solids, 47 (1999) 1157-1185.

[7] P. Longère, A. Dragon, Mechanics of Materials, 80, Part B (2015) 203-218.

[8] D. Rittel, Z. Wang, Mechanics of materials, 40 (2008) 629-635.

[9] Longhui Zhang, Daniel Rittel, S. Osovski, Materials Science \& Engineering A, 729 (2018) 94-101. 
[10] D. Rittel, L.H. Zhang, S. Osovski, J Mech Phys Solids, 107 (2017) 96-114.

[11] J. Noble, B. Goldthorpe, P. Church, J. Harding, J Mech Phys Solids, 47 (1999) 1187-1206.

[12] G. Mirone, Mechanics of Materials, 58 (2013) 84-96.

[13] J. Kajberg, B. Wikman, Int J Solids Struct, 44 (2007) 145-164.

[14] V. Tarigopula, O. Hopperstad, M. Langseth, A. Clausen, F. Hild, Int J Solids Struct, 45 (2008) 601-619.

[15] J. Qin, R. Chen, X. Wen, Y. Lin, M. Liang, F. Lu, Materials Science \& Engineering A, 586 (2013) 62-70.

[16] S. Tzibula, Z. Lovinger, D. Rittel, Mechanics of Materials, 123 (2018) 30-42.

[17] J. Yuan, V. Shim, Int J Solids Struct, 39 (2002) 213-224.

[18] R. Gerlach, C. Kettenbeil, N. Petrinic, International Journal of Impact Engineering, 50 (2012) 63-67.

[19] A. Pellegrino, V.L. Tagarielli, R. Gerlach, N. Petrinic, International Journal of Impact Engineering, 75 (2015) 214-221.

[20] Steven James, Yoji Kosaka, Roger Thomas, P. Garratt, Timetal® 407: A Titanium Alloy to Enable Cost Reduction, Proceedings of the 13th World Conference on Titanium, 2016.

[21] W. Davey, M. Bache, H. Davies, M. Thomas, MATEC Web Conf., 165 (2018) 04001.

[22] G.T. Gray, III, Classic Split-Hopkinson Pressure Bar Testing, in: H. Kuhn, D. Medlin (Eds.) Mechanical Testing and Evaluation, ASM International, 2000, pp. 0.

[23] F. De Cola, A. Pellegrino, C. Glößner, D. Penumadu, N. Petrinic, Exp Mech, 58 (2018) 223-242.

[24] G. Mirone, D. Corallo, R. Barbagallo, International Journal of Impact Engineering, 103 (2017) 180-194.

[25] W. Zhang, Z. Xu, Z. Sun, Y. Tong, F. Huang, Explosion and Shock Waves, 38 (2018) $1137-1144$.

[26] Z. Xu, X. He, H. Hu, P.J. Tan, Y. Liu, F. Huang, International Journal of Impact Engineering, 130 (2019) 281-291.

[27] G.R. Johnson, W.H. Cook, Eng Fract Mech, 21 (1985) 31-48.

[28] A.S. Khan, Y. Sung Suh, R. Kazmi, International Journal of Plasticity, 20 (2004) 2233 2248 .

[29] A.S. Khan, R. Kazmi, B. Farrokh, International Journal of Plasticity, 23 (2007) 931-950.

[30] D. Rittel, Mechanics of Materials, 31 (1999) 131-139. 
[31] D. Macdougall, J. Harding, International Journal of Impact Engineering, 21 (1998) 473488.

[32] V. Abaqus, Dassault Systemes Simulia Corporation, 651 (2014).

[33] M.L. Wilkins, Computer simulation of dynamic phenomena, Springer Science \& Business Media, 2013.

[34] F. Dunne, N. Petrinic, Introduction to computational plasticity, Oxford University Press on Demand, 2005.

[35] M.A. Meyers, Dynamic behavior of materials, John wiley \& sons, 1994.

[36] A. Dorogoy, D. Rittel, Exp Mech, 49 (2009) 881-885.

[37] W.-S. Lee, C.-F. Lin, Materials Science \& Engineering A, 241 (1998) 48-59.

[38] A. Vaz-Romero, Y. Rotbaum, J. Rodríguez-Martínez, D. Rittel, J Mech Phys Solids, 91 (2016) 216-239.

[39] P. Bridgman, McGraw-Hi/J, New York, (1952).

[40] G. Mirone, Int J Solids Struct, 41 (2004) 3545-3564.

[41] G. Mirone, D. Corallo, Eng Fract Mech, 102 (2013) 118-145.

[42] R. Liang, A.S. Khan, International Journal of Plasticity, 15 (1999) 963-980.

[43] V.S. Krasnikov, A.E. Mayer, International Journal of Plasticity, 74 (2015) 75-91.

[44] N. Petrinic, J.C. Sosa, C. Siviour, B. Elliott, Journal de Physique IV (Proceedings), EDP sciences, 2006, pp. 147-155. 